\title{
FY12 Final Report for PL10-Mod Separations-PD12: Electrochemically Modulated Separation of Plutonium from Dilute and Concentrated Dissolver Solutions for Analysis by Gamma Spectroscopy
}

SH Pratt

LM Arrigo

DC Duckworth

PM: JM Cloutier

May 2013
AT Breshears

JM Schwantes 


\title{
DISCLAIMER
}

This report was prepared as an account of work sponsored by an agency of the United States Government. Neither the United States Government nor any agency thereof, nor Battelle Memorial Institute, nor any of their employees, makes any warranty, express or implied, or assumes any legal liability or responsibility for the accuracy, completeness, or usefulness of any information, apparatus, product, or process disclosed, or represents that its use would not infringe privately owned rights. Reference herein to any specific commercial product, process, or service by trade name, trademark, manufacturer, or otherwise does not necessarily constitute or imply its endorsement, recommendation, or favoring by the United States Government or any agency thereof, or Battelle Memorial Institute. The views and opinions of authors expressed herein do not necessarily state or reflect those of the United States Government or any agency thereof.

\author{
PACIFIC NORTHWEST NATIONAL LABORATORY \\ operated by \\ BATTELLE \\ for the \\ UNITED STATES DEPARTMENT OF ENERGY \\ under Contract DE-AC05-76RL01830
}

Printed in the United States of America
Available to DOE and DOE contractors from the Office of Scientific and Technical Information,
P.O. Box 62, Oak Ridge, TN 37831-0062;
ph: (865) 576-8401
fax: $(865)$ 576-5728
email: reports@adonis.osti.gov

\begin{abstract}
Available to the public from the National Technical Information Service, U.S. Department of Commerce, 5285 Port Royal Rd., Springfield, VA 22161 ph: (800) 553-6847 fax: $(703) 605-6900$ email: orders@ntis.fedworld.gov online ordering: http://www.ntis.gov/ordering.htm
\end{abstract}

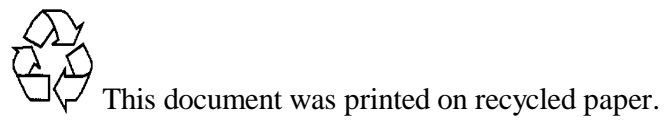




\section{FY12 Final Report for PL10-Mod Separations-PD12: \\ Electrochemically Modulated Separation of Plutonium from Dilute and Concentrated Dissolver Solutions for Analysis by Gamma Spectroscopy}

SH Pratt

LM Arrigo

DC Duckworth

PM: JM Cloutier
AT Breshears

JM Schwantes

May 2013

Prepared for

the U.S. Department of Energy

under Contract DE-AC05-76RL01830

Pacific Northwest National Laboratory

Richland, Washington 99352 


\section{Executive Summary}

Accurate and timely analysis of plutonium in spent nuclear fuel is critical in nuclear safeguards for detection of both protracted and rapid plutonium diversions. Gamma spectroscopy is a viable method for accurate and timely measurements of plutonium provided that the plutonium is well separated from the interfering fission and activation products present in spent nuclear fuel. Electrochemically modulated separation (EMS) is a method that has been used successfully to isolate picogram amounts of Pu from $U$ in nitric acid matrices. With EMS, Pu adsorption may be turned "on" and "off" depending on the applied voltage, allowing for collection and stripping of Pu without the addition of chemical reagents. In this work, we have scaled up the EMS process to isolate microgram quantities of $\mathrm{Pu}$ from matrices encountered in spent nuclear fuel during reprocessing. Several challenges have been addressed including surface area limitations, radiolysis effects, electrochemical cell performance stability, and chemical interferences. After these challenges were resolved, $6 \mu \mathrm{g} \mathrm{Pu}$ was deposited in the electrochemical cell with approximately an 800 -fold reduction of fission and activation product levels from a spent nuclear fuel sample. Modeling showed that these levels of $\mathrm{Pu}$ collection and interference reduction were not quite sufficient for direct Pu detection by gamma spectroscopy. The main remaining challenges are to achieve a more complete $\mathrm{Pu}$ isolation and to deposit larger quantities of $\mathrm{Pu}$ for successful gamma analysis of Pu. If gamma analyses of Pu are successful, EMS will allow for accurate and timely on-site analysis for enhanced Pu safeguards. 
PNNL-22539

\section{Abbreviations and Acronyms}

$\begin{array}{ll}\text { CE } & \text { counter electrode } \\ \text { DA } & \text { destructive analysis } \\ \text { EMS } & \text { electrochemically modulated separation } \\ \text { ICP-MS } & \text { inductively coupled plasma mass spectrometry } \\ \text { MIC } & \text { membrane isolation cell } \\ \text { NDA } & \text { non-destructive analysis } \\ \text { RE } & \text { reference electrode } \\ \text { SF } & \text { separation factor } \\ \text { simfuel } & \text { simulated spent fuel } \\ \text { TOF } & \text { time-of-flight } \\ \text { WE } & \text { working electrode }\end{array}$




\section{Contents}

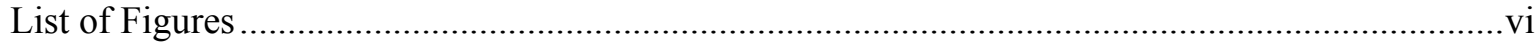

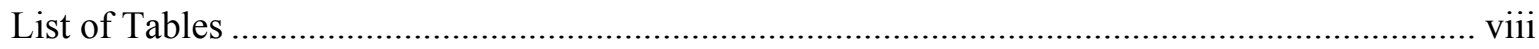

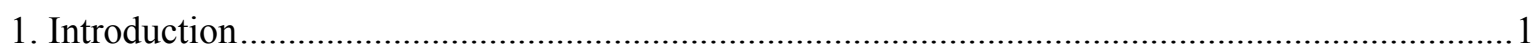

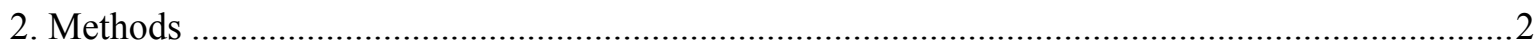

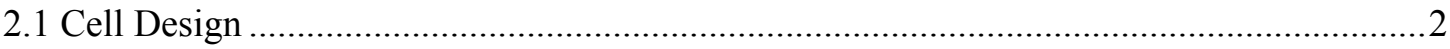

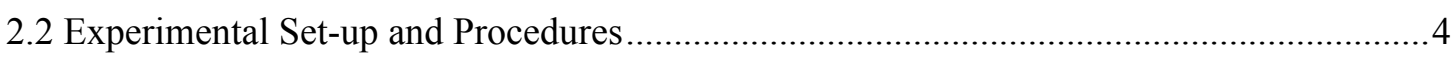

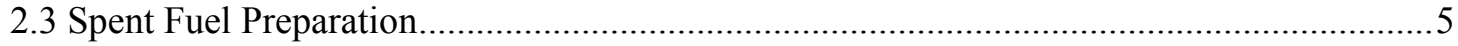

3. Progress in Testing Dilute and Concentrated Dissolver Solution (Tasks 2 and 4) ......................5

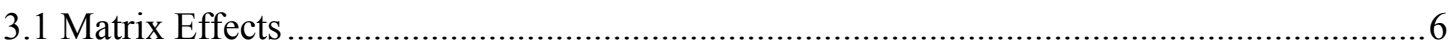

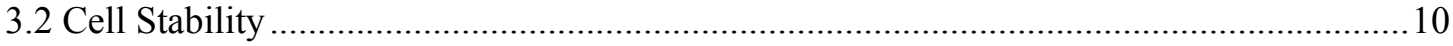

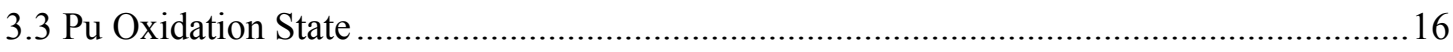

4. Progress in Gamma Spectroscopy (Task 5) ........................................................................ 21

4.1 Monitoring of Fission Products by Gamma Spectroscopy …...........................................21

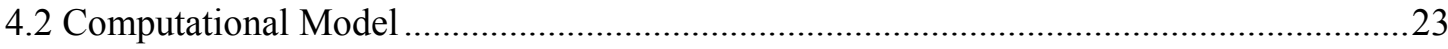

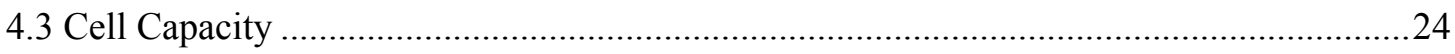

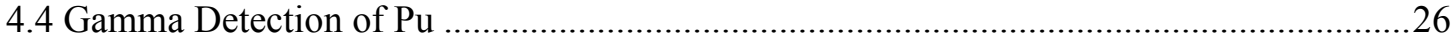

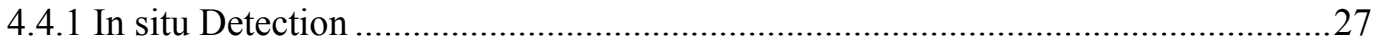

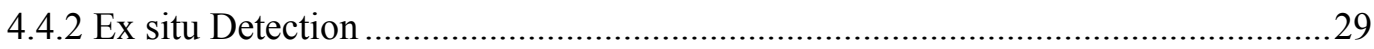

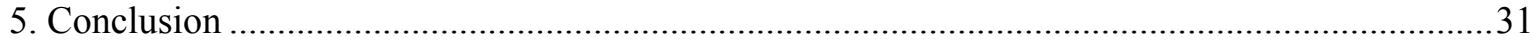

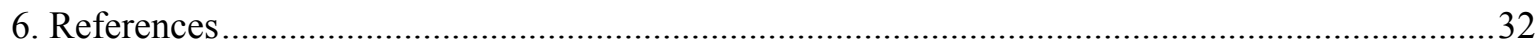




\section{List of Figures}

Figure 1. Envisioned implementation of Pu EMS for spent fuel: Safeguards in reprocessing. Apparatus footprint $<1 \mathrm{~m}^{2}$.

Figure 2. EMS principle: $\mathrm{Pu}^{3+}$ is oxidized to $\mathrm{Pu}^{4+}$ for deposition. $\mathrm{Pu}^{4+}$ is reduced to $\mathrm{Pu}^{3+}$ for stripping.

Figure 3. Membrane isolation cell (MIC) diagram. The working electrode was a glassy carbon plate, which was anodized. The counter electrode was an aluminum block. The reference electrode was $\mathrm{Ag} / \mathrm{AgCl}$ and was housed in the aluminum block. Dimensions shown are in centimeters.

Figure 4. Experimental set-up for real-time analysis with the MIC. 4

Figure 5. EMS profile of neat $238 \mathrm{ppb} U$ in $0.3 \mathrm{M}$ nitric acid (blue trace) and simulated spent fuel with $238 \mathrm{ppb} U$ in $0.3 \mathrm{M}$ nitric acid (red trace). Dashed line represents

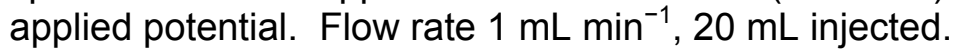

Figure 6. Effect of the mass of injected $U$ on the amount of $U$ that is deposited with neat $238 \mathrm{ppb} U$ in $0.3 \mathrm{M}$ nitric acid (blue) and simulated spent fuel with $238 \mathrm{ppb} U$ in 0.3

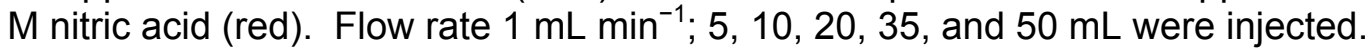

Figure 7. Effect of individual spent fuel components on Pu deposition efficiency. All cations tested were $10 \mathrm{ppm}$. Pu concentration was $100 \mathrm{ppt}$.

Figure 8. Stability of $U$ deposition in the MIC with the stainless steel counter electrode (blue) and the aluminum counter electrode (red). The dashed line shows a break in the cell usage.

Figure 9. Stability of $U$ deposition in the MIC over seven days using the aluminum counter electrode. A, B, C, D, and E groups are first, second, third, fourth, and seventh days. The linear trend line is shown. A loss of stability was observed on the fourth day (D) due to a loss of counter electrolyte flow. Outliers are represented by open circles and excluded from the trend line.

Figure 10. Cyclic voltammogram of $0.3 \mathrm{M}$ nitric acid in the MIC with stainless steel (blue trace) and aluminum (red trace) counter electrodes. Scan rate $100 \mathrm{mV} \mathrm{s}^{-1}$, counter electrolyte $1 \mathrm{M} \mathrm{NaCl}$.

Figure 11. Chronopotentiograms of $0.3 \mathrm{M}$ nitric acid in the $\mathrm{MIC}$ with aluminum (red trace) and stainless steel (green trace) counter electrodes. Left: deposition current applied (+1.2 mA), right: stripping current applied (-4.5 mA). Both have $1 \mathrm{M} \mathrm{NaCl}$ as the counter electrolyte.

Figure 12. Cyclic voltammograms of $0.3 \mathrm{M}$ nitric acid in the MIC with the aluminum counter electrode and varying counter electrolytes. Green: $1 \mathrm{M} \mathrm{Nal}$, red: $1 \mathrm{M} \mathrm{NaBr}$, and blue: $1 \mathrm{M} \mathrm{NaCl}$. Scan rate $100 \mathrm{mV} \mathrm{s}^{-1}$.

Figure 13. Effect of the counter electrolyte on $U$ deposition efficiency of the MIC with the aluminum counter electrode. All electrolytes were the sodium salt and $1 \mathrm{M}$.

Figure 14. Effect of time and spent fuel concentration on the percent of plutonium in the +4 oxidation state according to Eq. 6, assuming a starting point of $100 \% \mathrm{Pu}^{4+}$ and $0.3 \mathrm{M}$ nitric acid. Undiluted spent fuel is assumed 0.0126 M Pu with an internal dose of $20 \mathrm{~W} / \mathrm{L}$. 
Figure 15. Analysis of EMS fractions by ICP-TOF-MS. Blue trace: $\mathrm{Pu}^{4+}$ was produced by electrochemical reduction of $\mathrm{PuO}_{2}{ }^{2+}$ at $-0.5 \mathrm{~V}$; Red trace: $\mathrm{PuO}_{2}{ }^{2+}$ was produced by addition of $1 \mathrm{mg} \mathrm{AgO}$ to $100 \mathrm{ppt} \mathrm{Pu}$ in $3 \mathrm{M} \mathrm{HNO}_{3}$. Pu was accumulated at $+1.1 \mathrm{~V}$ and stripped at $-0.2 \mathrm{~V}$.

Figure 16. Effect of reduction potential on the percent of $\mathrm{PuO}_{2}{ }^{2+}$ reduced to $\mathrm{Pu}^{3+}$ in the MIC.

Figure 17. The effect of hydrogen peroxide on the amount of $\mathrm{PuO}_{2}{ }^{2+}$ reduced to $\mathrm{Pu}^{4+}$ as observed by the resulting deposition efficiency for $\mathrm{Pu}$. $\mathrm{H}_{2} \mathrm{O}_{2}$ was added to $10 \mathrm{~mL}$ of $100 \mathrm{ppt} \mathrm{PuO}_{2}{ }^{2+}$

Figure 18. Gamma spectra showing the Cs-137 peak (661.64 KeV) in spent fuel in the outlet tubing of the MIC (red trace), compared with the background spectrum (blue trace). Count time was 5 minutes. Top: first spectrum, middle: second spectrum, bottom: third spectrum.

Figure 19. Modeled gamma spectra of Pu in spent fuel with different degrees of separation from Cs-137. Green: no separation, Red: separation factor $=100$, Blue: separation factor $=10,000$.

Figure 20. Three dimensional plots from a computational model indicating the effect of separation factors and Pu mass on the uncertainty associated with Pu gamma spectroscopy measurements. Top: Pu-239, middle: Pu-238, bottom: Pu-240. Note the logarithmic scales.

Figure 21. EMS-ICP-TOF-MS profile for $500 \mathrm{ppb} \mathrm{U}$ in $0.3 \mathrm{M} \mathrm{HNO}_{3}$. Flow rate $1 \mathrm{~mL}$ $\mathrm{min}^{-1}$. Potential applied was $+0.4 \mathrm{~V}$ to 5 minutes, followed by $-0.2 \mathrm{~V}$ to $1 \mathrm{~h} 15$ minutes, followed by $+1.1 \mathrm{~V}$. Mass marks indicate how much $\mathrm{U}$ was deposited. Counts are normalized to a strip peak height of $100 \%$.

Figure 22. Effect of $U$ injected on $U$ accumulated. $U$ concentration was $238 \mathrm{ppb}$ (blue) and $500 \mathrm{ppb}$ (green). Dotted line shows asymptote of fit curve and MIC capacity for U.

Figure 23. Diagram of the in situ EMS-gamma experiment set-up.

Figure 24. Photograph of the in situ EMS-gamma experiment. Inset photograph is the gamma probe and tubing coil.

Figure 25. Gamma spectra from in situ monitoring of the EMS coil with a Nal detector. Count time 15 minutes.

Figure 26. Gamma spectra for spent fuel break-through fraction. Count time 24 hours. Peaks were identified by Apex-Gamma software.

Figure 27. Gamma spectra for spent fuel strip fraction. Count time 24 hours. Peaks were identified by Apex-Gamma software. Pu peak locations marked with dashed lines. Red: Pu-238, Purple: Pu-240, Green: Pu-239, Blue: Pu-241. 
PNNL-22539

\section{List of Tables}

Table 1. Pu deposition efficiency results for the dissolver solution tests with suspected reasons for poor $\mathrm{Pu}$ deposition and progress towards solving the problems. Red: no progress, orange: some progress, green: problem solved.

Table 2. Dissolver solution ATM-109 (high burn-up $\sim 60-70$ gigawatt-days/metric ton of

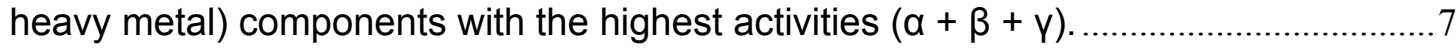

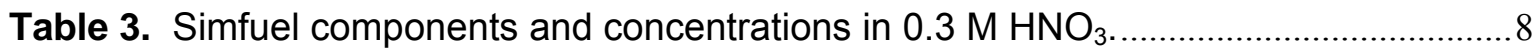

Table 4. Deposition efficiencies for $U$ in the MIC with stainless steel and aluminum counter electrodes using chronoamperometry and chronopotentiometry..................... 14

Table 5. Isotope $\mathrm{y}$ activities in break-through, rinse, and strip fractions............................30 


\section{Introduction}

The accurate and timely detection of plutonium during reprocessing is important to nuclear safeguards. Currently, detection of Pu in spent fuel is accomplished by both non-destructive analysis (NDA) and destructive analysis (DA). NDA measurements, such as hybrid K-edge densitometry (Ottmar and Eberle 1991), are rapid since they require little to no sample preparation. However, hybrid K-edge densitometry does not provide isotopic data and the instrumentation is very expensive. Also, NDA methods are less precise than DA methods, such as mass spectrometry, and are therefore less sensitive to protracted diversions of Pu. Mass spectrometry, however, requires laboratory-based separations and is therefore not cost-effective or timely, making it less sensitive to detection of rapid material diversion.

There is still a need for more rapid and precise methods for material accountability. Electrochemically modulated separation (EMS) is being investigated as a relatively straight-forward method for at-line separation coupled with NDA as a means to reduce the risk of rapid and protracted diversion of special nuclear material.

EMS is a flow-through separation method that could be placed at-line with a reprocessing stream to isolate $\mathrm{Pu}$ and enable at-line radioanalysis (e.g., low-energy gamma spectroscopy). EMS may also be used to isolate Pu prior to mass spectrometry analysis and increase the sample through-put for DA. A diagram of the envisioned system is shown in Figure 1.

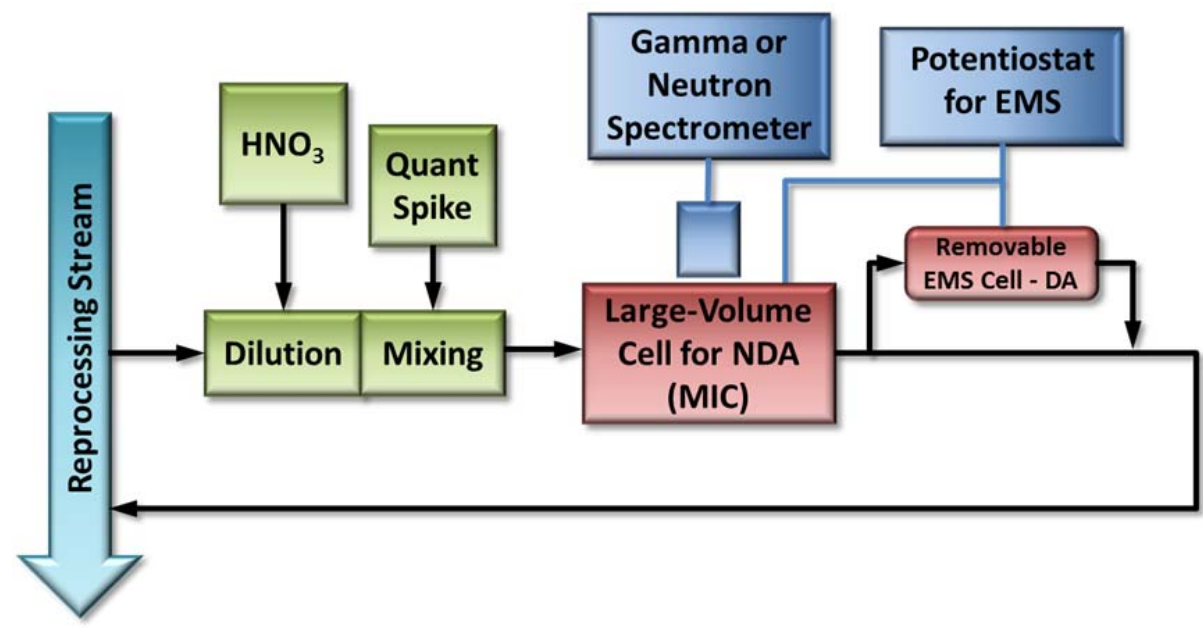

Figure 1. Envisioned implementation of Pu EMS for spent fuel: Safeguards in reprocessing. Apparatus footprint $<1 \mathrm{~m}^{2}$.

EMS has been demonstrated for both uranium and plutonium at an anodized glassy carbon working electrode (WE) (Pretty, et al. 1998; Clark, et al. 2006; Duckworth, et al. 2008; Green et al. 2009). Both $U$ and Pu have the greatest affinity for oxidized surfaces, such as anodized glassy carbon surface, in the +4 oxidation state (Schwantes 2002). For $\mathrm{Pu}$, the +4 oxidation state is maintained at an oxidizing potential; for $U$, the +4 oxidation state is maintained at a reducing potential. Therefore, separation of $U$ and 
Pu readily occurs even though they adsorb by very similar mechanisms. A diagram of the Pu EMS process is shown in Figure 2. $\mathrm{Pu}^{3+}$ is injected into the EMS flow-through cell while a positive potential is applied. $\mathrm{Pu}^{3+}$ is oxidized to $\mathrm{Pu}^{4+}$ which adsorbs to the anodized glassy carbon surface. To effect Pu desorption, a negative potential is applied and $\mathrm{Pu}^{4+}$ is reduced to $\mathrm{Pu}^{3+}$. EMS is often employed in-line with inductively coupled plasma mass spectrometry (ICP-MS) supporting process diagnostics and method development. In this case, the Pu counts increase as a volume, concentrated in $\mathrm{Pu}$, is released. A transient peak is observed (Figure 2, bottom) since $\mathrm{Pu}$ is released into a smaller volume then that from which it was collected, effectively pre-concentrating the analyte.

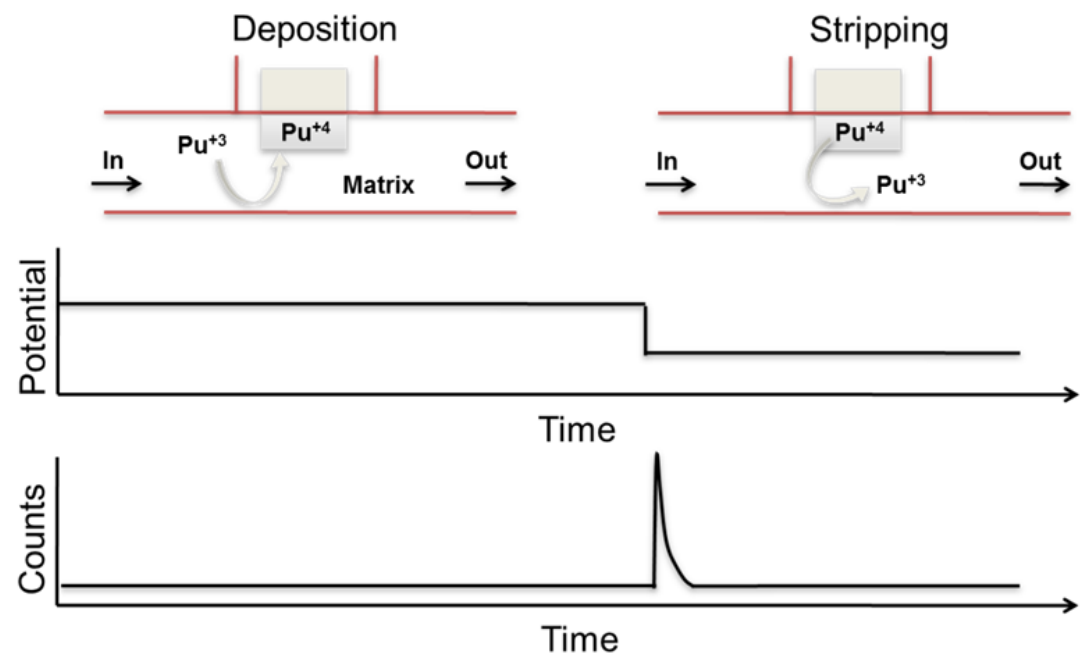

Figure 2. EMS principle: $\mathrm{Pu}^{3+}$ is oxidized to $\mathrm{Pu}^{4+}$ for deposition. $\mathrm{Pu}^{4+}$ is reduced to $\mathrm{Pu}^{3+}$ for stripping.

EMS experiments were performed to selectively separate $\mathrm{Pu}$ from spent fuel using only electrochemically driven redox reactions. Spent fuel is a very complex matrix and several challenges were encountered including matrix effects, cell stability, and radioloysis of $\mathrm{Pu}$ that affected the oxidation state and therefore the Pu separation. Each challenge has been at least partially addressed and results are encouraging with respect to the potential for success in a hybrid, at-line NDA method for material accountability measurements.

\section{Methods}

\subsection{Cell Design}

Pu EMS was accomplished in a $15 \times 13 \times 6 \mathrm{~cm}$ membrane isolation cell (MIC) (Figure 3). The unique features of the MIC are the surface area, allowable flow rate, and the anion-exchange membrane ( $400 \mu \mathrm{m}$ thick) which serves to isolate the opposing electrochemical reactions that occur on the counter electrode (CE). 

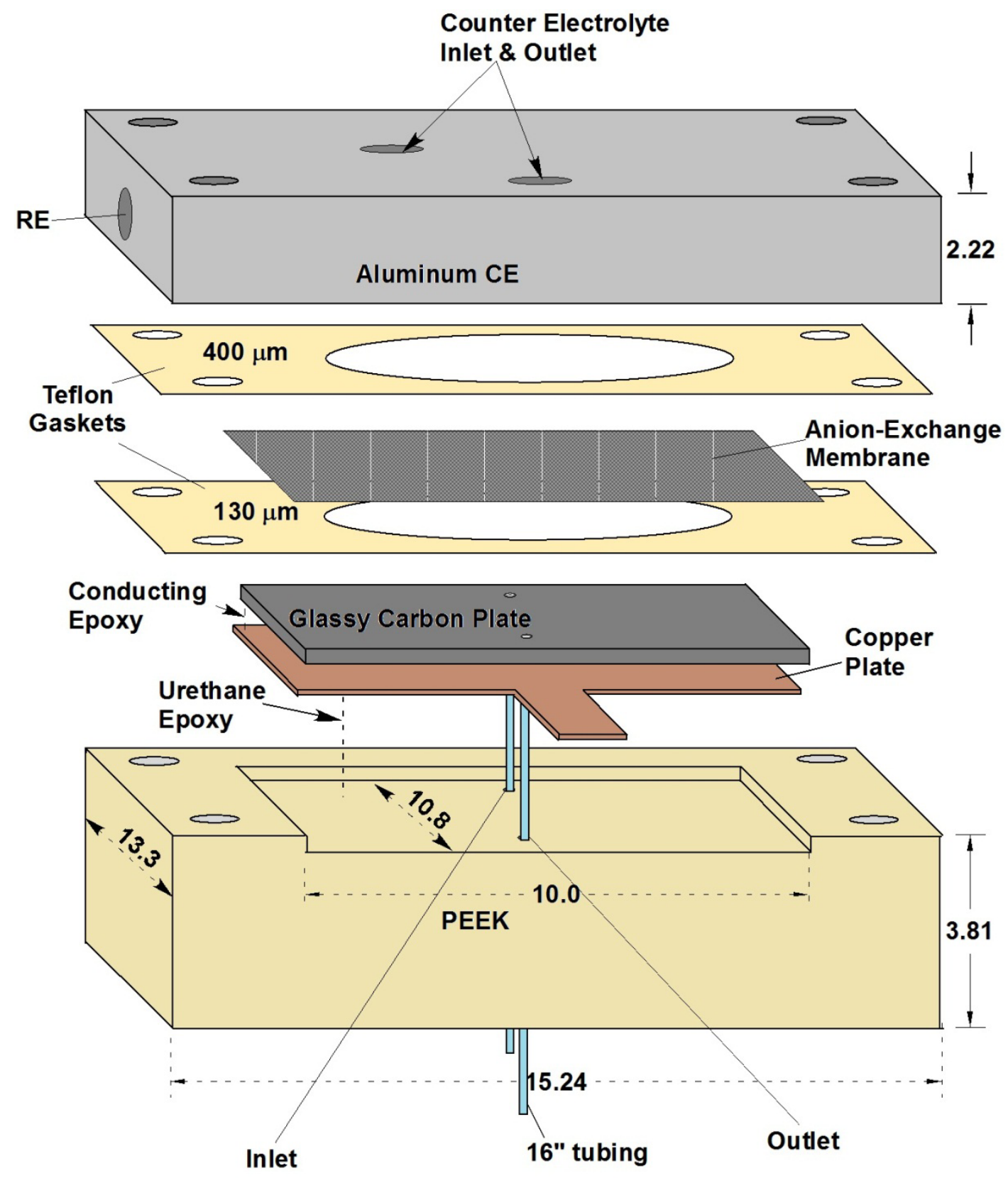

Figure 3. Membrane isolation cell (MIC) diagram. The working electrode was a glassy carbon plate, which was anodized. The counter electrode was an aluminum block. The reference electrode was $\mathrm{Ag} / \mathrm{AgCl}$ and was housed in the aluminum block. Dimensions shown are in centimeters.

Because the anion-exchange membrane is permeable to anions but not cations, it allows for good charge mobility between the counter and working electrodes. At the same time, the positively charged $\mathrm{Pu}$ ions and counter electrode corrosion products were confined to their respective areas. By using the membrane to isolate the counter electrode, the dead volume of the cell was decreased, giving improved deposition kinetics and efficiencies. The exposed area of the anodized glassy carbon working 
electrode (WE) is approximately $45 \mathrm{~cm}^{2}$ and the volume approximately $0.6 \mathrm{~mL}$ with a $130 \mu \mathrm{m}$ gasket. A reference electrode (RE) is housed in the counter electrode. A counter electrolyte $(1.0 \mathrm{M} \mathrm{NaCl})$ circulated through the cell between the membrane and the counter electrode. A flow equal to the sample flow was maintained for the counter electrolyte. The constant flow served to equalize pressure on both sides of the membrane, renew the counter electrolyte, and prevent the build-up of gases.

\subsection{Experimental Set-up and Procedures}

EMS experiments were performed by two different methods: (1) in-line with ICPMS and (2) off-line fraction collection and analysis. The experimental set-up for an inline analysis is shown in Figure 4. This experimental design was useful for near realtime analysis. The ICP-MS used had an inductively coupled plasma time-of-flight mass analyzer (ICP-TOF-MS) which allowed for monitoring of all sample components simultaneously and in real-time.

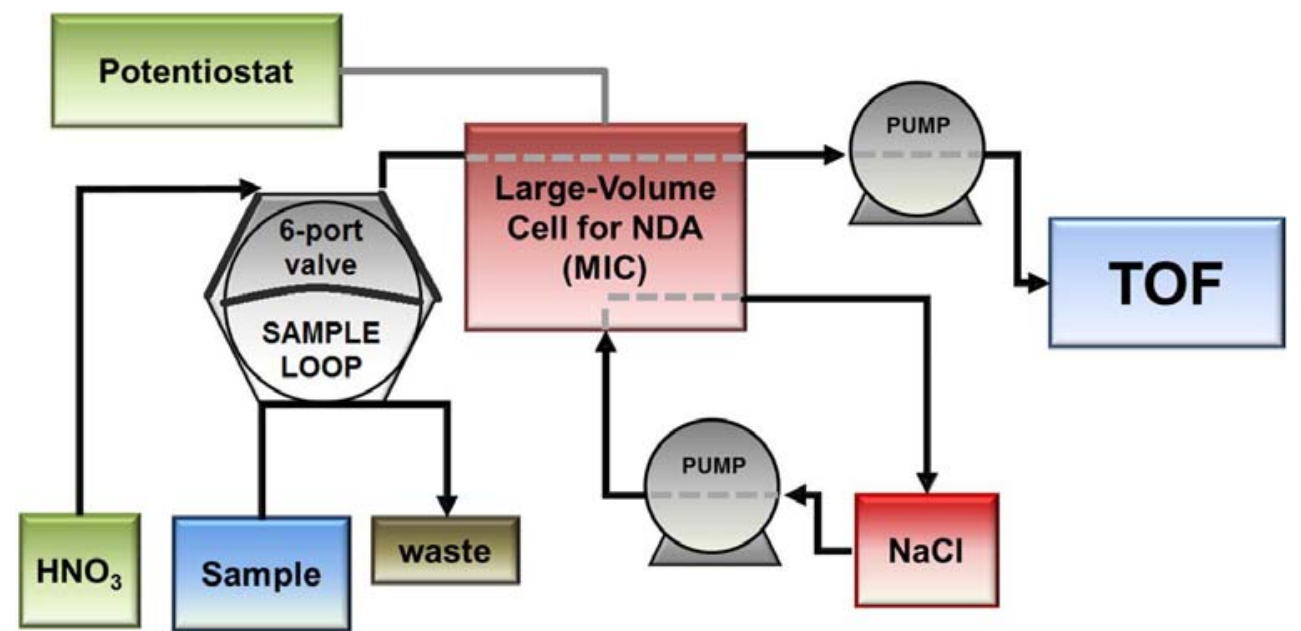

Figure 4. Experimental set-up for real-time analysis with the MIC.

Most experiments were performed in an off-line configuration in which fractions were collected and analyzed. These experiments were accomplished by injecting 1.0 $\mathrm{mL}$ of $\mathrm{U}$ or Pu solution in $0.3 \mathrm{M}$ nitric acid into the MIC with the appropriate accumulation potential applied $(+1.1 \mathrm{~V}$ for $\mathrm{Pu},-0.2 \mathrm{~V}$ for $\mathrm{U})$. Samples were spiked with $\mathrm{Ho}$ (non-adsorbing and not redox active) in order to normalize $\mathrm{Pu}$ and $\mathrm{U}$ counts later in the mass spectrometry measurements. The sample was followed by a rinse with neat $0.3 \mathrm{M}$ nitric acid. The volume of the cell effluent collected was usually $10 \mathrm{~mL}$. Once the accumulation fraction was collected a new collection vial was used and a stripping potential was applied to the working electrode $(-0.2 \mathrm{~V}$ for $\mathrm{Pu},+1.1 \mathrm{~V}$ for $\mathrm{U})$. Another 10 $\mathrm{mL}$ of cell effluent was collected for the strip fraction. These two fractions were analyzed by mass spectrometry, along with a control, which was a sample injected into the cell at open-circuit potential. Deposition efficiency was calculated by the difference in the normalized counts of Pu in the control and the normalized counts of Pu in the accumulation fraction divided by the normalized Pu counts in the control. 


\subsection{Spent Fuel Preparation}

The spent fuel sample ATM-109 was a thin wafer, approximately $1 \mathrm{~cm}$ in diameter by $2 \mathrm{~mm}$ thick weighing $1.05 \mathrm{~g}$, cut from a spent fuel rod, including the cladding. The wafer was dissolved in $5 \mathrm{~mL}$ of hot $12 \mathrm{M} \mathrm{HNO}_{3}$. After $2 \mathrm{~h}$ of heating the solution was allowed to cool overnight, then diluted to $14.5 \mathrm{~mL}$ with deionized water. The undissolved cladding was removed. A $0.1 \mathrm{~mL}$ aliquot of the dissolved spent fuel solution was taken and diluted to $5 \mathrm{~mL}$. This 50 -fold diluted stock was used to make all successive spent fuel dilutions.

\section{Progress in Testing Dilute and Concentrated Dissolver Solution (Tasks 2 and 4)}

Initial experiments efficiently separated Pu-244 from neat solutions or simulated spent fuel. Optimization of the cell parameters, such as flow rate, gasket thickness, anodization time, anodization medium, and counter electrolyte concentration, were performed using uranium as a surrogate. When the optimized parameters were used in neat solutions and simulated spent fuel, deposition efficiencies for Pu were typically near $70 \%$. However, the exact same parameters gave near $0 \%$ deposition efficiencies when used with real dilute spent fuel samples.

Four dissolver solution tests were performed in the course of the project, with significant challenges being addressed after every test (Table 1). However, sufficient progress for observable Pu separation was not observed until the fourth dissolver solution test conducted in December 2012.

Table 1. Pu deposition efficiency results for the dissolver solution tests with suspected reasons for poor Pu deposition and progress towards solving the problems. Red: no progress, orange: some progress, green: problem solved.

\begin{tabular}{|l|c|c|c|c|}
\hline \multirow{2}{*}{$\begin{array}{l}\text { Hypothesized } \\
\text { Problem }\end{array}$} & \multicolumn{4}{|l|}{ Status after... } \\
\cline { 2 - 5 } & $\begin{array}{l}\text { Dissolver } \\
\text { Solution Test \#1 }\end{array}$ & $\begin{array}{l}\text { Dissolver } \\
\text { Solution Test \#2 }\end{array}$ & $\begin{array}{l}\text { Dissolver } \\
\text { Solution Test \#3 }\end{array}$ & $\begin{array}{l}\text { Dissolver } \\
\text { Solution Test \#4 }\end{array}$ \\
\hline \%DE & $2 \pm 1 \%$ & $0.9 \pm 0.1 \%$ & $0 \%$ & $18 \pm 3 \%$ \\
\hline Matrix Effect & Possible & Possible & $\begin{array}{c}\text { Partially } \\
\text { Ruled Out }\end{array}$ & $\begin{array}{c}\text { Partially } \\
\text { Ruled Out }\end{array}$ \\
\hline Cell Stability & Possible & Work Around & Resolved & Resolved \\
\hline $\begin{array}{l}\text { Pu Oxidation } \\
\text { State }\end{array}$ & Possible & Possible & $\begin{array}{c}\text { Highly } \\
\text { Possible }\end{array}$ & $\begin{array}{c}\text { Partially } \\
\text { Resolved }\end{array}$ \\
\hline
\end{tabular}


Three issues were believed to be possible reasons for the poor Pu deposition: (1) matrix effects, (2) cell stability, and (3) the initial plutonium oxidation state. After the first dissolver solution test, the cell stability was targeted as a likely reason for poor $\mathrm{Pu}$ deposition. During uranium separation experiments, the cell always lost $100 \%$ of its separation efficiency over several hours. It had appeared as though leaving the cell idle or without flow for more than 20 minutes accelerated efficiency loss. Because the cell stability problem could not be immediately resolved, the second dissolver solution test was performed very quickly without allowing the cell to sit idle in attempt to work around the degrading efficiency.

Poor Pu deposition was observed again in the second dissolver solution test, therefore a simulated spent fuel solution analysis was revisited to isolate a possible matrix effect. No strong matrix effects were uncovered that could account for the $0 \%$ deposition efficiency of Pu. However, matrix effects could not be completely ruled out because the exact elemental composition of the spent fuel was not known.

It was between the second and third dissolver solution tests that an aluminum counter electrode was tested. The aluminum counter electrode, in the place of stainless steel, provided improved stability in the cell performance, fully resolving that particular problem for the third dissolver solution test.

With matrix effects partially ruled out and the cell stability problem resolved, the initial Pu oxidation state was highly suspect. Therefore, the third dissolver solution test was designed to highlight the Pu oxidation state problem. A Pu-244 spike was added to the spent fuel. The Pu-244 in the spike had been tested and was known to deposit, therefore, it was assumed to be $\mathrm{Pu}^{3+}$ or $\mathrm{Pu}^{4+}$. It was hypothesized that the $\mathrm{Pu}$ in the dissolver solution had been oxidized to $\mathrm{PuO}_{2}{ }^{2+}$, which will not deposit at positive potentials. The results of the experiment showed that Pu-244 spike accumulated with $70 \%$ efficiency while the dissolver solution $\mathrm{Pu}$ failed to deposit at all. This result suggested strongly that the main problem for poor Pu deposition was the Pu oxidation state. However, matrix effects could still not be ruled out. For example, an interfering ion forming an intermetallic compound with $\mathrm{Pu}$, preventing $\mathrm{Pu}$ deposition, may give the same result if the formation of the intermetallic compound was kinetically slow.

In the fourth dissolver solution test, an attempt was made to chemically reduce the $\mathrm{Pu}$ using hydrogen peroxide. The result, which showed approximately $20 \%$ deposition of $\mathrm{Pu}$, demonstrated that the $\mathrm{Pu}$ oxidation state was in fact the reason for limited Pu deposition. In addition, the result also suggests that the problem can be resolved, although improved reduction efficiency is desired.

\subsection{Matrix Effects}

Due to the complex matrix of the dissolver solution (Table 2), matrix effects were immediately suspect as potential problems. There are two mechanisms by which dissolver solution components may interfere: competitive binding and coordination. lons that co-deposit with Pu will compete for binding sites. Ions that coordinate with $\mathrm{Pu}$ in solution will prevent depostion if the coordination is stronger than the bond between $\mathrm{Pu}(\mathrm{IV})$ and the anodized glassy carbon surface of the WE. 
Table 2. Dissolver solution ATM-109 (high burn-up $\sim 60-70$ gigawatt-days/metric ton of heavy metal) components with the highest activities $(\alpha+\beta+\gamma)$.

\begin{tabular}{|c|c|c|c|c|c|}
\hline Isotope & $\begin{array}{c}\text { Acitivity } \\
\text { (Ci) }\end{array}$ & $\begin{array}{c}\text { Specific } \\
\text { Activity } \\
\text { (Ci/g) }\end{array}$ & $\begin{array}{c}\text { Measured } \\
\text { Mass (g) }\end{array}$ & PPM & PPM Totals \\
\hline Am-241 & 3.31E-05 & $3.20 E+00$ & $9.74 \mathrm{E}-06$ & $1.95 E+00$ & \multirow{4}{*}{$4.09 E+00$} \\
\hline Am-242 & 8.33E-08 & & $1.03 E-13$ & 2.06E-08 & \\
\hline Am-242m & 8.37E-08 & & 8.37E-09 & 1.67E-03 & \\
\hline Am-243 & 2.14E-06 & 1.90E-01 & 1.07E-05 & $2.14 \mathrm{E}+00$ & \\
\hline Ba-137m & 2.07E-03 & & $3.83 E-12$ & 7.66E-07 & 7.66E-07 \\
\hline $\mathrm{Cm}-242$ & 6.89E-08 & $3.30 E+03$ & 2.09E-11 & 4.18E-06 & \multirow{5}{*}{ 9.08E-01 } \\
\hline $\mathrm{Cm}-243$ & $6.38 \mathrm{E}-07$ & $4.20 E+00$ & 1.23E-08 & 2.46E-03 & \\
\hline $\mathrm{Cm}-244$ & 3.39E-04 & $8.20 E+01$ & 4.19E-06 & 8.38E-01 & \\
\hline $\mathrm{Cm}-245$ & 3.70E-08 & $1.00 \mathrm{E}-01$ & 2.18E-07 & 4.36E-02 & \\
\hline $\mathrm{Cm}-246$ & 3.76E-08 & 3.60E-01 & 1.21E-07 & 2.42E-02 & \\
\hline Cs-134 & 2.53E-05 & $1.20 E+03$ & 1.95E-08 & 3.90E-03 & \multirow{2}{*}{$5.04 \mathrm{E}+00$} \\
\hline Cs-137 & 2.19E-03 & $9.80 E+01$ & 2.52E-05 & $5.04 \mathrm{E}+00$ & \\
\hline Eu-154 & 4.51E-05 & $1.50 E+02$ & 1.73E-07 & $3.46 \mathrm{E}-02$ & \multirow{2}{*}{ 3.85E-02 } \\
\hline Eu-155 & 9.44E-06 & $1.40 E+03$ & 1.93E-08 & 3.86E-03 & \\
\hline $\mathrm{H}-3$ & 8.57E-06 & $9.70 \mathrm{E}+03$ & $8.84 \mathrm{E}-10$ & 1.77E-04 & 1.77E-04 \\
\hline $\mathrm{Kr}-85$ & 6.58E-05 & $4.00 E+02$ & 1.69E-07 & 3.38E-02 & 3.38E-02 \\
\hline Np-239 & $2.14 \mathrm{E}-06$ & $2.30 E+05$ & $9.30 \mathrm{E}-12$ & 1.86E-06 & 1.86E-06 \\
\hline $\mathrm{Pm}-147$ & $3.11 \mathrm{E}-05$ & $9.40 E+02$ & 3.34E-08 & 6.68E-03 & 6.68E-03 \\
\hline Pu-238 & 9.29E-05 & $1.70 E+01$ & 5.46E-06 & $1.09 E+00$ & \multirow{5}{*}{$3.03 E+01$} \\
\hline Pu-239 & 3.27E-06 & $6.20 \mathrm{E}-02$ & 5.27E-05 & $1.05 E+01$ & \\
\hline Pu-240 & 1.15E-05 & 2.30E-01 & 5.00E-05 & $1.00 \mathrm{E}+01$ & \\
\hline Pu-241 & 8.19E-04 & $1.10 E+02$ & 8.19E-06 & $1.64 \mathrm{E}+00$ & \\
\hline Pu-242 & 1.36E-07 & 3.90E-03 & 3.49E-05 & $6.98 E+00$ & \\
\hline Rh-106 & 2.28E-07 & & $6.33 \mathrm{E}-17$ & $1.27 \mathrm{E}-11$ & $1.27 \mathrm{E}-11$ \\
\hline Ru-106 & 2.28E-07 & $3.40 E+03$ & $6.71 \mathrm{E}-11$ & 1.34E-05 & 1.34E-05 \\
\hline Sb-125 & 3.02E-06 & $1.40 E+03$ & 3.02E-09 & 6.04E-04 & 6.04E-04 \\
\hline Sm-151 & 4.01E-06 & $2.60 \mathrm{E}+01$ & $1.54 \mathrm{E}-07$ & 3.08E-02 & 3.08E-02 \\
\hline Sn-121 & 3.02E-07 & & $3.16 \mathrm{E}-13$ & 6.32E-08 & \multirow{2}{*}{ 1.44E-03 } \\
\hline Sn-121m & 3.89E-07 & & 7.20E-09 & $1.44 \mathrm{E}-03$ & \\
\hline Sr-90 & 1.15E-03 & $1.50 \mathrm{E}+02$ & 8.21E-06 & $1.64 \mathrm{E}+00$ & $1.64 \mathrm{E}+00$ \\
\hline Tc-99 & 3.85E-07 & 1.70E-02 & 2.26E-05 & $4.52 E+00$ & $4.52 \mathrm{E}+00$ \\
\hline Te-125m & 7.38E-07 & $4.00 E+04$ & $4.10 \mathrm{E}-11$ & 8.20E-06 & 8.20E-06 \\
\hline$Y-90$ & 1.15E-03 & $2.50 E+05$ & 2.13E-09 & 4.26E-04 & 4.26E-04 \\
\hline
\end{tabular}

In order to test the effects of other ions on Pu deposition, a simulated spent fuel solution (simfuel) was prepared per a recipe in the literature (Tomiyasu and Asano, 1998). The simfuel represented an approximately 3,000-fold dilution for all components except for uranium, which was 300,000 times less than the actual spent fuel stock at $238 \mathrm{ppb}$, or $1 \mu \mathrm{M}$ for ${ }^{238} \mathrm{U}$. The simfuel components and their concentrations are listed in Table 3. 
Table 3. Simfuel components and concentrations in $0.3 \mathrm{M} \mathrm{HNO}_{3}$.

\begin{tabular}{|c|c|c|}
\hline Component (Surrogate for...) & $\begin{array}{l}\text { Concentration, } \\
\text { ppb }\end{array}$ & Co-Deposits with...(U, Pu) \\
\hline $\mathbf{U}$ & $238=1 \mu \mathrm{M}$ & \\
\hline Cs & 96 & \\
\hline $\mathbf{R b}$ & 14 & \\
\hline $\mathrm{Sr}$ & 26 & \\
\hline $\mathrm{Ba}$ & 53 & \\
\hline $\mathbf{Y}$ & 16 & \\
\hline $\operatorname{La}(A m, C m)$ & 40 & \\
\hline $\mathrm{Ce}(N p)$ & 78 & \\
\hline $\mathrm{Pr}$ & 39 & \\
\hline Nd & 135 & \\
\hline Sm & 25 & \\
\hline Ru & 74 & $\mathrm{U}, \mathrm{Pu}$ \\
\hline $\mathbf{R h}$ & 13 & $\mathrm{U}, \mathrm{Pu}$ \\
\hline Pd & 32 & U \\
\hline $\mathrm{Zr}$ & 115 & $U$ \\
\hline Mo & 113 & $U$ \\
\hline $\operatorname{Re}(T c)$ & 26 & U \\
\hline Te & 14 & $\mathrm{U}, \mathrm{Pu}$ \\
\hline Ho (internal standard) & 100 & \\
\hline Eu (Internal standard) & 100 & \\
\hline
\end{tabular}

In the initial experiment uranium was tested for matrix effects since $U$ is naturally occurring and therefore more readily available at high concentrations where the effects were more easily observed. When the deposition profiles (Figure 5) of neat uranium in $0.3 \mathrm{M} \mathrm{HNO}_{3}$ and simfuel were compared, the interference was apparent, but not severe. Figure 5 shows the flow injections of $238 \mathrm{ppb}$ uranium in the two matrices in-line with the ICP-TOF-MS. Upon application of the deposition potential, approximately $50 \%$ of the $U$ is adsorbed on the anodized glassy carbon, resulting in a 50\% drop in the MS signal. The signal then begins to rise with an increase in the break-through of $U$, which is due to the decrease in free binding sites as the electrode surface approaches saturation. With the simfuel, the saturation occurs more quickly because of the competition for binding sites between $\mathrm{U}$ and those ions that co-deposit (namely $\mathrm{Ru}, \mathrm{Rh}$, $\mathrm{Pd}, \mathrm{Zr}, \mathrm{Mo}, \mathrm{Re}$, and $\mathrm{Te}$ ).

Furthermore, the amount of $U$ injected has an effect on the interference from the simfuel components (Figure 6). For up to $3 \mu \mathrm{g}$ of $\mathrm{U}$ injected, the simfuel components have no discernible effect. However, when more than $3 \mu \mathrm{g}$ of $U$ is injected, deposition efficiency for the neat $U$ and the simfuel begin to diverge.

Based on Figure 5 and Figure 6, it may be inferred that the matrix effect for $\mathrm{U}$ deposition is due to competitive binding. In Figure 5, the initial drop in signal for both matrices is the same and the divergence only occurs as the electrode becomes saturated. If the interference occurred due to intermetallic coordination, there would be 
a difference between the two matrices as soon as the deposition was initiated. Likewise, in Figure 6, an intermetallic coordination interference would have affected any amount of $U$ injected, not just at trace levels.

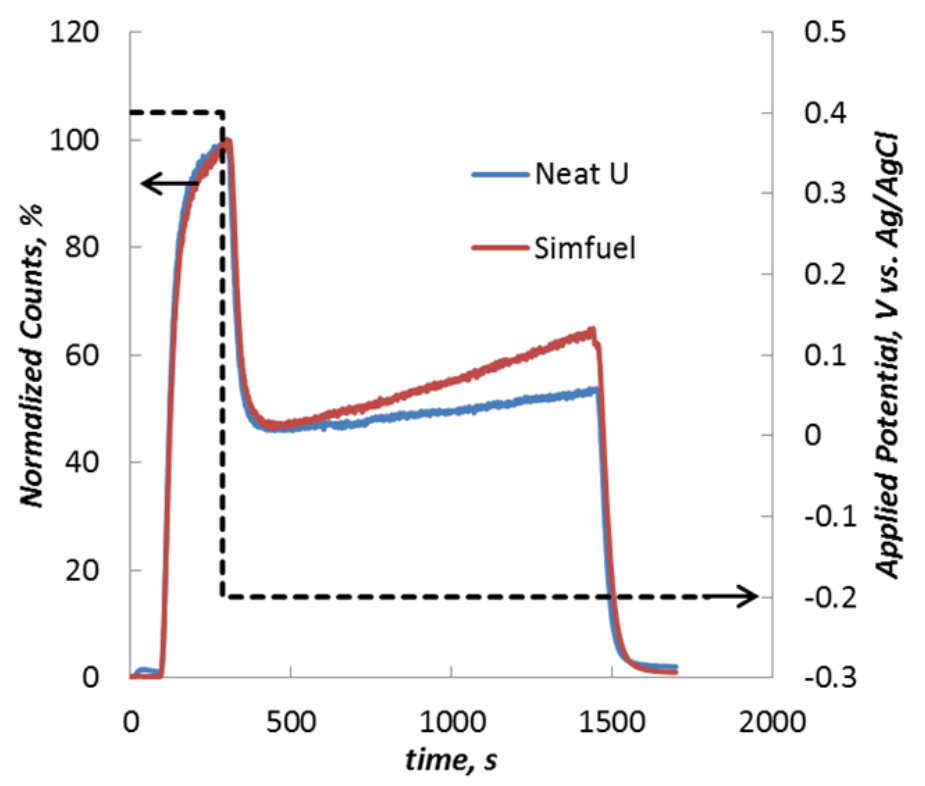

Figure 5. EMS profile of neat $238 \mathrm{ppb} \mathrm{U}$ in $0.3 \mathrm{M}$ nitric acid (blue trace) and simulated spent fuel with $238 \mathrm{ppb} \mathrm{U}$ in $0.3 \mathrm{M}$ nitric acid (red trace). Dashed line represents

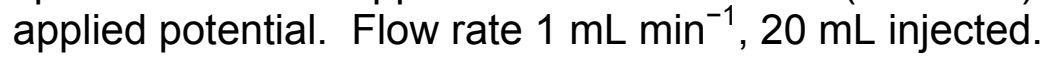

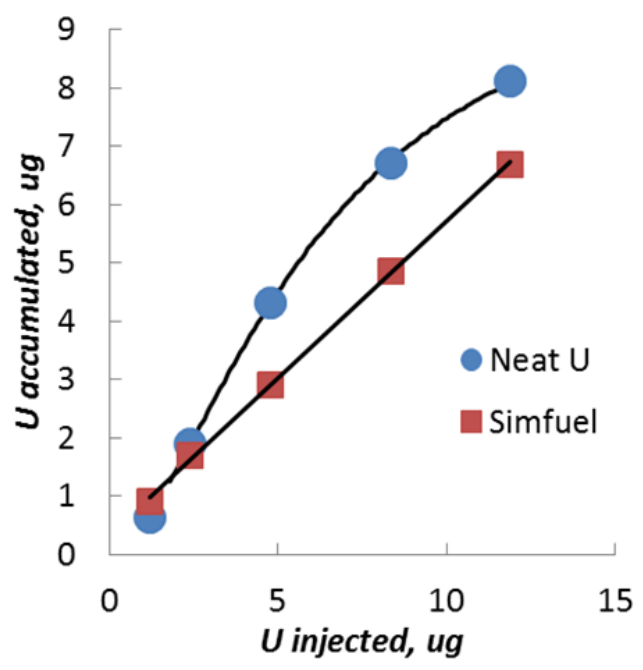

Figure 6. Effect of the mass of injected $U$ on the amount of $U$ that is deposited with neat $238 \mathrm{ppb} \mathrm{U}$ in $0.3 \mathrm{M}$ nitric acid (blue) and simulated spent fuel with $238 \mathrm{ppb} \mathrm{U}$ in 0.3

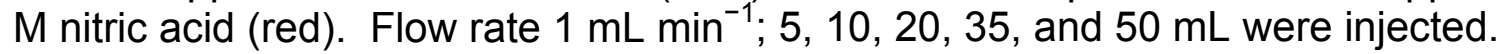

Fewer simfuel components deposit under conditions favoring Pu compared with the conditions that favor $U$. This is not surprising since $U$ deposits at negative potentials. Many transition metals can be electrochemically deposited in elemental form by application of negative potentials. Because there are fewer metals that co-deposit 
with $\mathrm{Pu}$, the simfuel components were expected to have less of an interfering effect on $\mathrm{Pu}$. In an off-line experiment, this effect was proven. A neat solution of $100 \mathrm{ppt} \mathrm{Pu}$ deposited with $70 \pm 10 \%$ efficiency and 100 ppt $\mathrm{Pu}$ in simfuel also deposited with 70 $\pm 10 \%$ efficiency. However, higher concentrations of Pu may not be as resilient against competitive binding since more Pu will require more binding sites.

Individual simfuel components were also tested for interference with $\mathrm{Pu}$ deposition at higher concentrations-10 ppm, compared with $100 \mathrm{ppt}$ for $\mathrm{Pu}-\mathrm{a}$ 100,000 -fold excess (Figure 7). The only obvious interference was $\mathrm{Zr}$, while $\mathrm{Rb}, \mathrm{Sr}$, and Ba may have also shown a slight interference. None of the simfuel components were found to interfere with Pu deposition at the $1 \mathrm{ppm}$ level, which is a better approximation of the levels expected in the working spent fuel solution. It is interesting that some ions, such as Mo and Re actually appeared to increase Pu deposition efficiencies. This may be due to an intermetallic compound that forms on the glassy carbon surface, and require further investigation.

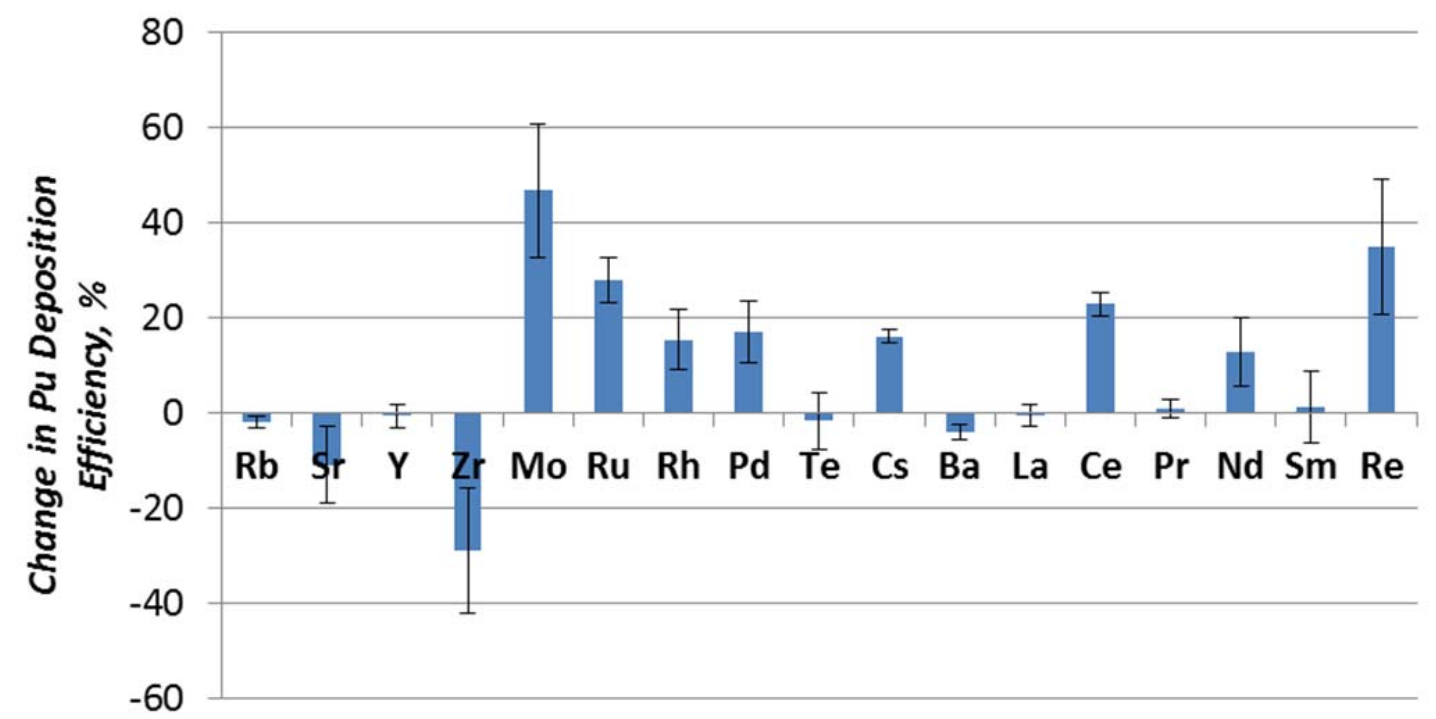

Figure 7. Effect of individual spent fuel components on Pu deposition efficiency. All cations tested were $10 \mathrm{ppm}$. Pu concentration was $100 \mathrm{ppt}$.

It is important to be aware of these observed matrix effects in future spent fuel experiments. Matrix effects may be a concern with high concentrations of spent fuel. However, they clearly could not account for the near-zero percent deposition of $\mathrm{Pu}$ observed in the first three dissolver solution tests. The cell stability, on the other hand, was a problem capable of diminishing deposition efficiency to zero.

\subsection{Cell Stability}

Prior to the first dissolver solution test, it had been observed that the MIC deposition efficiency for uranium would always decrease to zero after less than 12 
hours. Sometimes the decrease seemed random, but usually it occurred after the cell was not in use for more than 20 minutes. In contrast, the small electrochemical cell routinely used for picogram amounts of Pu typically operates efficiently for months and hundreds of accumulations. Many attempts were made to avoid the loss of separation efficiency, including: continued the electrolyte flow, cycling cell potential, and using nitric acid as the counter electrolyte. None of these steps reduced the loss of accumulation efficiency. However, no matter how poor the MIC's performance was, it could always be regained by re-anodizing the glassy carbon working electrode. This observation led us to suspect (wrongly) that the problem was at the working electrode when it was actually in the counter electrode.

The stability problem would eventually be solved serendipitously when experimenting with alternate counter electrode materials. In order to provide a more transparent window for in situ gamma spectroscopy, aluminum had to be used for the counter electrode instead of stainless steel. When the aluminum counter electrode was used, the cell stability problem was solved (Figure 8). Unfortunately, the benefits of the aluminum were not discovered until after the second dissolver solution test. This meant that cell operating lifetime problems could not be ruled out as a reason for the poor $\mathrm{Pu}$ deposition efficiencies in the first two dissolver solution tests. With the aluminum counter electrode, the MIC could withstand idle times of greater than 30 minutes. In fact, performance of the MIC would last for days without re-anodization of the working electrode (Figure 9) with the aluminum counter electrode. Furthermore, even if performance was lost, as in Group D in Figure 9, when the counter electrolyte went dry, it could be regained by replenishing the counter electrolyte.

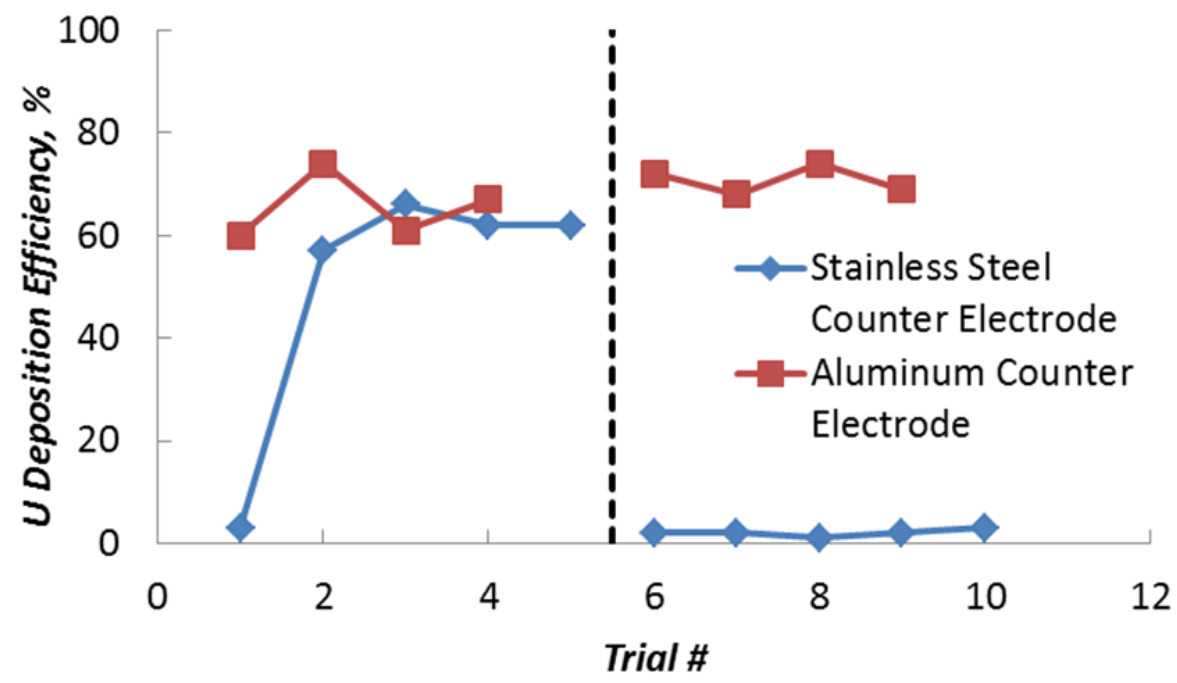

Figure 8. Stability of $U$ deposition in the MIC with the stainless steel counter electrode (blue) and the aluminum counter electrode (red). The dashed line shows a break in the cell usage.

Two possible reasons for the difference between aluminum and stainless steel counter electrodes were hypothesized: (1) the $\mathrm{Fe}, \mathrm{Cr}, \mathrm{Ni}$ and $\mathrm{Mo}$ ions from the dissolution of stainless steel were creating an interference, or (2) the conductivity of 
aluminum is superior to that of stainless steel. The first hypothesis was easily tested by adding dissolved stainless steel to the counter electrolyte when the aluminum counter electrode was used. No effect was observed. $\left(\mathrm{Al}^{3+}\right.$ was also added to the counter electrolyte when the stainless steel counter electrode was used to determine whether the stability would be improved. It was not.)

Though the resistivity of aluminum alloy $7075\left(3.7 \times 10^{-8} \Omega\right)$ is lower than that of 316 stainless steel $\left(7.5 \times 10^{-7} \Omega\right)$ (Eddy Current Technology Incorporated), the difference is not so great that it can account of the difference in behavior of the two counter electrodes. Even though stainless steel has 20 times greater resistivity, both aluminum and stainless steel have very low resistivity and should be acceptable counter electrodes based on the text book values.

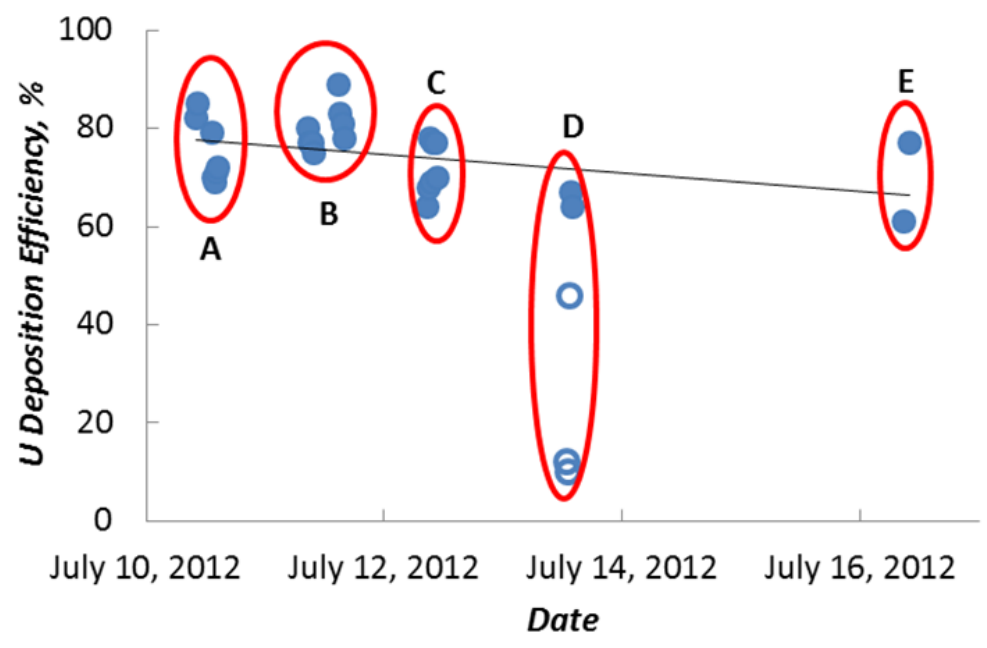

Figure 9. Stability of $U$ deposition in the MIC over seven days using the aluminum counter electrode. A, B, C, D, and E groups are first, second, third, fourth, and seventh days. The linear trend line is shown. A loss of stability was observed on the fourth day (D) due to a loss of counter electrolyte flow. Outliers are represented by open circles and excluded from the trend line.

However, the electrochemical behavior does indicate a much greater uncompensated resistance, $R_{\mathrm{u}}$, in the MIC with the stainless steel counter electrode compared with the aluminum counter electrode (Figure 10). The greater $R_{\mathrm{u}}$ manifests itself as lower current in a cyclic voltammogram if it becomes significant enough to affect the applied potential according to Eq. 1.

$E_{\text {actual }}=E_{\text {applied }}-i R_{\mathrm{u}}$

$E_{\text {actual }}$ is the actual potential bias at the working electrode, $E_{\text {applied }}$ is the potential setting for the working electrode according to the potentiostat, and $i$ is current. As seen in the equation, with any non-zero current, if the uncompensated resistance is high, the potentiostat setting and the actual potential can differ significantly. When $E_{\text {actual }}<<$ $E_{\text {applied, }}$, the current will also be very low because the working electrode never achieves 
much greater than open-circuit potential in the most extreme case. This is what appeared to be happening when the stainless steel electrode was in used in the MIC.

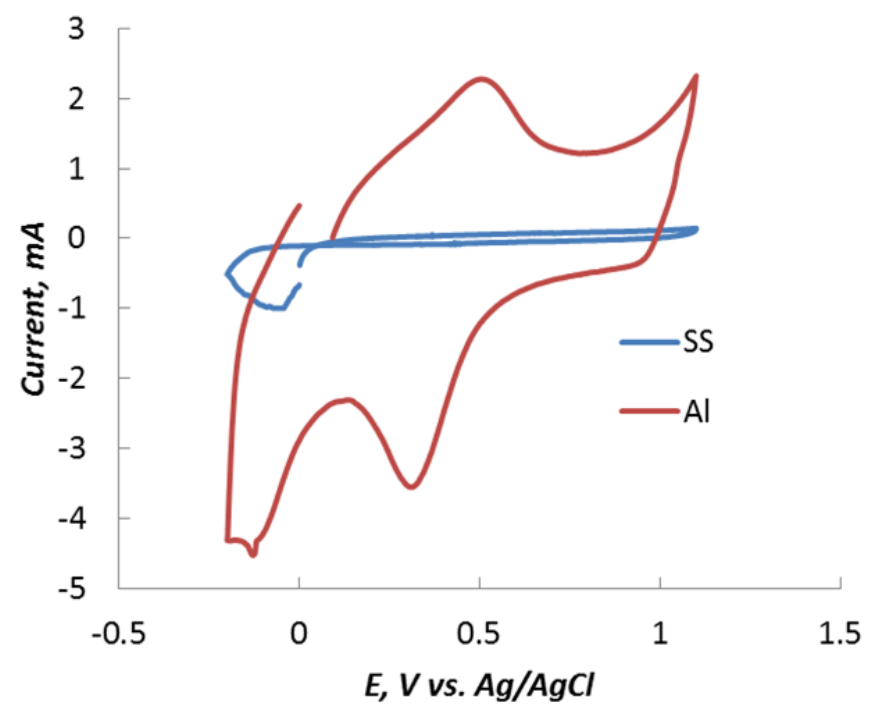

Figure 10. Cyclic voltammogram of $0.3 \mathrm{M}$ nitric acid in the MIC with stainless steel (blue trace) and aluminum (red trace) counter electrodes. Scan rate $100 \mathrm{mV} \mathrm{s}^{-1}$, counter electrolyte $1 \mathrm{M} \mathrm{NaCl}$.

One way to compensate for the high resistance is to apply a current rather than a potential. While potential is affected by high $R_{\mathrm{u}}$, current is not. Therefore, when a potential is applied and a current is measured, the measured current is correct but the applied potential is incorrect. However, in chronopotentiometry, a current is applied and a potential is measured (Figure 11).
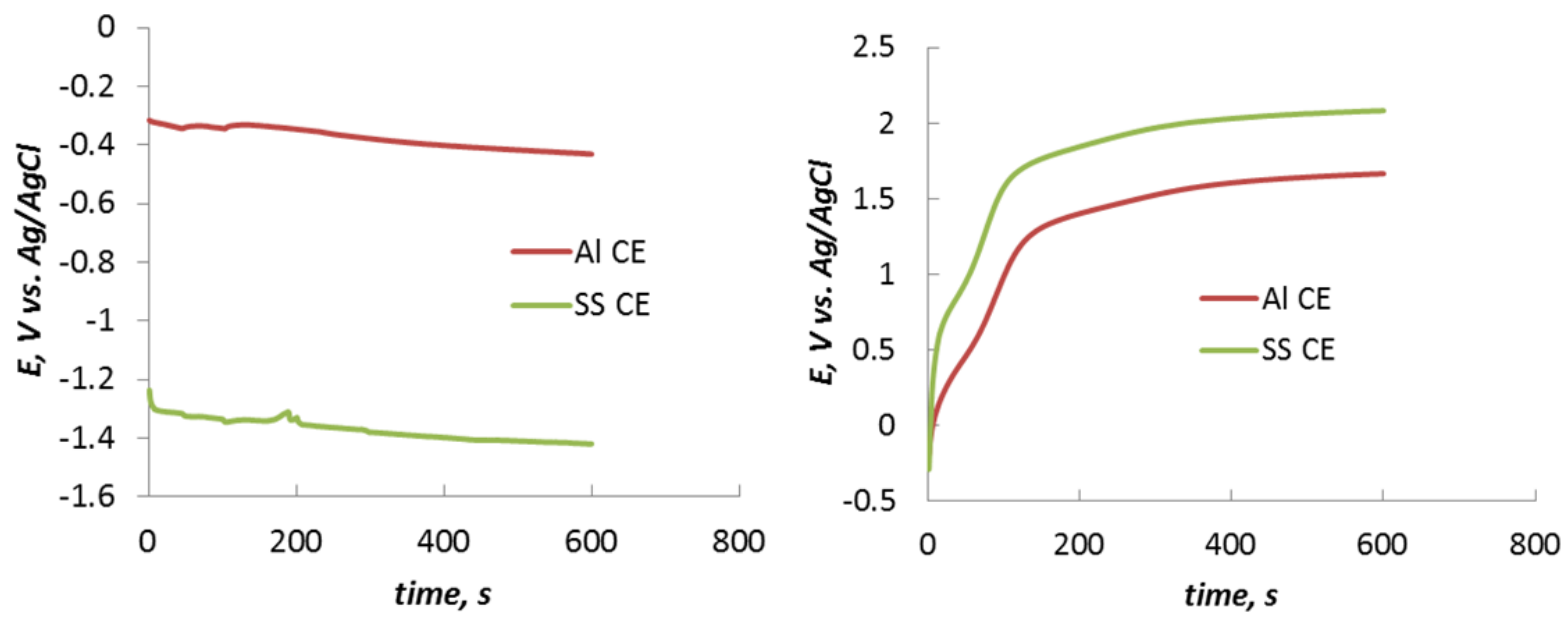

Figure 11. Chronopotentiograms of $0.3 \mathrm{M}$ nitric acid in the MIC with aluminum (red trace) and stainless steel (green trace) counter electrodes. Left: deposition current applied (+1.2 mA), right: stripping current applied $(-4.5 \mathrm{~mA})$. Both have $1 \mathrm{M} \mathrm{NaCl}$ as the counter electrolyte. 
Therefore, with high $R_{\mathrm{u}}$, the applied current will be correct but the measured potential will be incorrect. $U$ and Pu deposition are affected only by what is applied and not by what is measured. Using chronopotentiometry instead of chronoamperometry, the MIC performance was the same with both counter electrodes (Table 4). The only difference was that the potential measured for the stainless steel electrode was much greater with the same current applied, as shown in Figure 11.

Table 4. Deposition efficiencies for $U$ in the MIC with stainless steel and aluminum counter electrodes using chronoamperometry and chronopotentiometry.

\begin{tabular}{||l|l|l||}
\hline \hline & \multicolumn{2}{|l||}{ URANIUM DEPOSITION EFFICIENCY, \% } \\
\hline Method & Stainless Steel & Aluminum \\
\hline Applied Potential & $6 \pm 1$ & $63 \pm 7$ \\
\hline Applied Current & $72 \pm 5$ & $61 \pm 7$ \\
\hline
\end{tabular}

Chronoamperometry-applying a potential and measuring a current-may be used successfully with the stainless steel counter electrode. Using Figure 11, we have estimated the set potential required to apply the proper actual potential. For example, when the MIC with the aluminum electrode was at $-0.2 \mathrm{~V}$ (the deposition potential for uranium) the MIC with the stainless steel electrode was at $-1.2 \mathrm{~V}$. Likewise, when the MIC with the aluminum counter electrode was at $+1.0 \mathrm{~V}$, the MIC with the stainless steel electrode was at $+1.7 \mathrm{~V}$. Using a deposition potential of $-1.2 \mathrm{~V}$ and a stripping potential of $+1.7 \mathrm{~V}, \mathrm{U}$ deposition efficiency was $79 \pm 6 \%$ for the MIC with the stainless steel electrode with no sign of time-dependent instability.

It is important to note that when $-1.2 \mathrm{~V}$ and $+1.7 \mathrm{~V}$ were applied with the stainless steel counter electrode in place, the actual potentials were still approximately $-0.2 \mathrm{~V}$ and $+1.1 \mathrm{~V}$. Only the instrument setting was altered in order to compensate for the high surface resistance of the stainless steel counter electrode.

It is clear that stainless steel as the counter electrode for the MIC has unacceptably high resistance, while the aluminum counter electrode resistance is tolerable. The difference in resistivity cannot be explained by the bulk resistance of the two materials. The reason for the difference must then be in the surface resistivity.

Both stainless steel (Okamoto 1973) and aluminum (Britton and Evans 1930) form an inert metal oxide layer on their surfaces. In most applications, the inert film is a useful feature because it prevents corrosion. However, in electrodes, the film acts as a passivating layer that increases resistivity of the electrochemical cell, which was observed with stainless steel.

The lower resistivity of the MIC with the aluminum counter electrode is due to the corrosive nature of the $1 \mathrm{M} \mathrm{NaCl}$ electrolyte. As chloride is more corrosive to aluminum than to stainless steel, aluminum's inert metal oxide layer was stripped away more easily than the inert metal oxide layer on stainless steel. The ability of an anion to corrode aluminum is related to its ability to penetrate the $\gamma-\mathrm{Al}_{2} \mathrm{O}_{3}$ film. Britton and Evans found this order of anion penetrating ability (from highest ability): $\mathrm{Cl}^{-}, \mathrm{Br}^{-}, \mathrm{I}^{-}, \mathrm{F}^{-}, \mathrm{SO}_{4}{ }^{2-}$, $\mathrm{NO}_{3}{ }^{-}$, and $\mathrm{HPO}_{4}{ }^{2-}$. Using just the top three anions in the counter electrolyte for the MIC with the aluminum counter electrode showed a dramatic difference in cell conductivity (Figure 12). 
Furthermore, the order of penetrating ability corresponded well to the MIC's ability to separate uranium when different anions were used in the counter electrolyte (Figure 13). Chloride by far showed the best $U$ deposition response. Phosphate and nitrate in the counter electrolyte virtually eliminated the MIC's ability to separate uranium since aluminum was able to build up its inert oxide layer in those media.

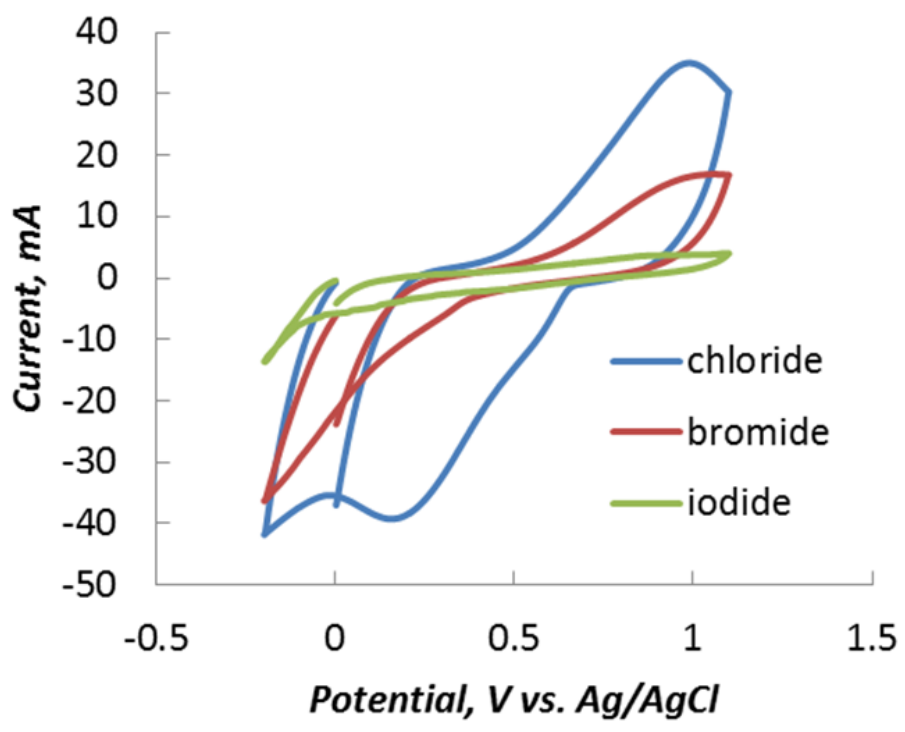

Figure 12. Cyclic voltammograms of $0.3 \mathrm{M}$ nitric acid in the MIC with the aluminum counter electrode and varying counter electrolytes. Green: $1 \mathrm{M} \mathrm{Nal}$, red: $1 \mathrm{M} \mathrm{NaBr}$, and blue: $1 \mathrm{M} \mathrm{NaCl}$. Scan rate $100 \mathrm{mV} \mathrm{s}^{-1}$.

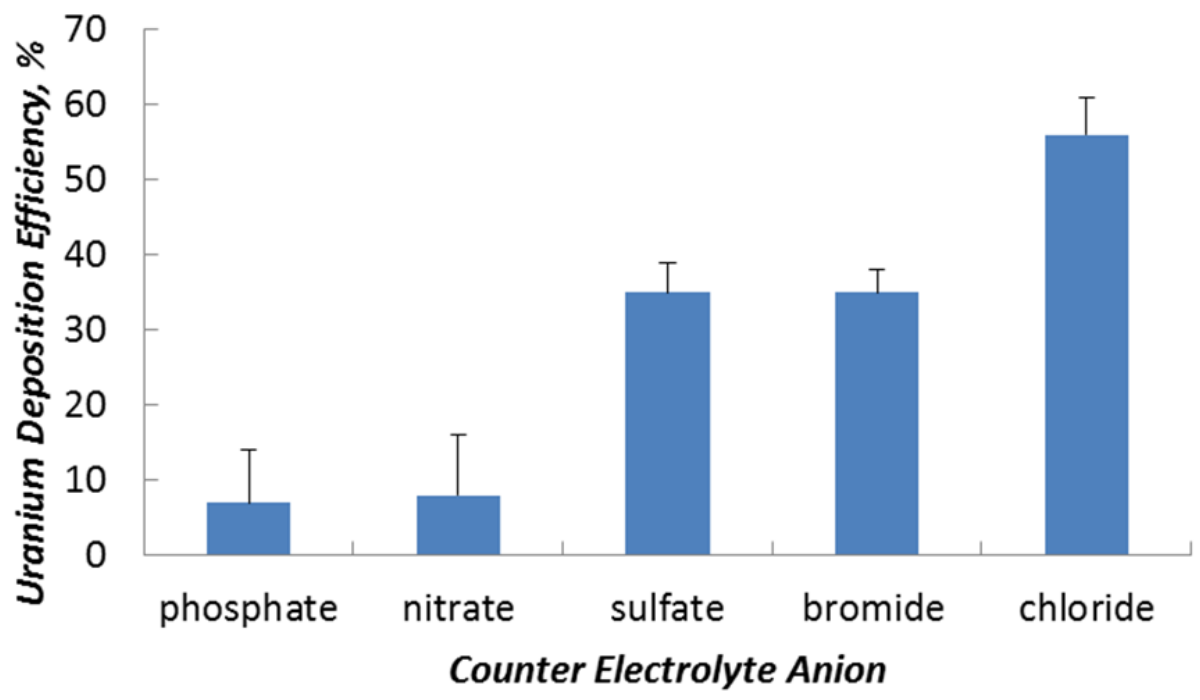

Figure 13. Effect of the counter electrolyte on $U$ deposition efficiency of the MIC with the aluminum counter electrode. All electrolytes were the sodium salt and $1 \mathrm{M}$. 
The ability of the MIC with the stainless steel electrode to regain performance after polishing and re-anodizing the glassy carbon electrode may also be explained by inert metal oxide film characteristics. It was not the glassy carbon working electrode treatment that caused the reversal, but the drying of the stainless steel counter electrode. While the glassy carbon was polished and anodized, the stainless steel counter electrode sat on the bench in open air and dried. At this time, the surface would lose adsorbed water to evaporation. The adsorbed water, when present, had provided a buffering effect against corrosion by chloride ions (Okamoto 1973).

When the cell was reassembled, the chloride ions in the counter electrolyte would attack the inert film, keeping the electrode conductive. However, after some time, enough water would be adsorbed to provide the necessary buffering to allow the stainless steel surface to regenerate the inert metal oxide layer again. Therefore, it was actually adsorption of water that caused the high resistivity of the MIC with the stainless steel counter electrode, along with the inability of chloride to penetrate the inert oxide film. Acidic chloride may have been able to break down the stainless steel's inert oxide layer and provide cell stability; however, $\mathrm{HCl}$ was never used as a counter electrolyte. A noble metal as a counter electrode would also certainly provide cell stability since noble metals do not form oxide layers. A deposited thin film of platinum or rhodium would be ideal.

One question remains largely unanswered, and that is why the MIC with the stainless steel electrode appeared to lose performance when it was not in use. The reason may have to do with the flow rates and potentials applied to the cell. Higher flow rates and potentials may have temporarily prevented water from adsorbing. However, these conditions probably only slowed the formation of the inert film and not prevented it. In experiments where the cell was not used for $U$ separation, but the flow rates and potential applications were maintained, good performance was not maintained.

In conclusion, by using the aluminum counter electrode in the MIC, the cell demonstrated excellent stability over the course of several days. Using the aluminum counter electrode in the third dissolver solution test, we could be confident that the cell was performing properly even though the deposition efficiency for spent fuel Pu was $0 \%$. This dissolver solution test also included a spike of Pu-244 which was collected with $70 \%$ efficiency. Therefore, the Pu in the spent fuel clearly had some difference from the Pu-244 in the spike. The most likely difference was the initial Pu oxidation state.

\subsection{Pu Oxidation State}

EMS of Pu depends on Pu existing in the +3 or +4 oxidation state. The electrochemical mechanism by which Pu deposits on the anodized glassy carbon is:

$\mathrm{Pu}^{3+}+[\mathrm{S}] \stackrel{+1.1 \mathrm{~V}}{\longrightarrow} \mathrm{Pu}^{4+}[\mathrm{S}]+\mathrm{e}^{-}$

$[\mathrm{S}]$ is the glassy carbon substrate to which $\mathrm{Pu}$ adsorbs. $\mathrm{Pu}^{4+}$ has the greatest affinity for the anodized glassy carbon surface, while $\mathrm{Pu}^{3+}$ has a very low affinity to it (Schwantes 
2002). Plutonium readily switches between $\mathrm{Pu}^{3+}$ and $\mathrm{Pu}^{4+}$, and a constant oxidizing potential is required to maintain the +4 oxidation state.

While $\mathrm{PuO}_{2}{ }^{2+}$ can be electrochemically produced from $\mathrm{Pu}^{4+}$ (Eq. 3), it is very difficult, requiring $+1.95 \mathrm{~V}$ applied for $3 \mathrm{~h}$ (Cohen 1961). The difficulty stems from required rearrangement of water.

$\mathrm{Pu}^{4+}+2 \mathrm{H}_{2} \mathrm{O} \stackrel{+1.95 \mathrm{~V}, 3 \mathrm{~h}}{\longrightarrow} \mathrm{PuO}_{2}^{2+}+4 \mathrm{H}^{+}+2 \mathrm{e}^{-}$

The kinetic behavior of $\mathrm{Pu}$ benefits the EMS mechanism profoundly. The desired $\mathrm{Pu}$ oxidation state, +4 , can be quickly created by applying a high overpotential without concern of creating a higher oxidation state $(+5,+6)$, although these are just as stable as $\mathrm{Pu}^{4+}$ and $\mathrm{Pu}^{3+}$ once created. $\mathrm{PuO}_{2}{ }^{2+}$ does not deposit at anodized glassy carbon. Furthermore, $\mathrm{PuO}_{2}{ }^{2+}$ cannot be electrochemically reduced directly to $\mathrm{Pu}^{4+}$. Therefore, when Pu exists in solution as $\mathrm{PuO}_{2}{ }^{2+}$, it does not undergo electrochemical accumulation.

Radiolysis by alpha radiation is known to cause oxidation of $\mathrm{Pu}$ in solution (Rykov, et al. 1979). The mechanism by which this occurs in a nitric acid medium is shown in Eq. $4-5$.

$2 \mathrm{NO}_{3}^{-} \stackrel{\alpha}{\rightarrow} 2 \mathrm{NO}_{2}+\mathrm{O}_{2}+2 \mathrm{e}^{-}$

$2 \mathrm{NO}_{2}+\mathrm{Pu}^{4+}+2 \mathrm{H}_{2} \mathrm{O} \rightarrow 2 \mathrm{NO}_{2}^{-}+\mathrm{PuO}_{2}^{2+}+4 \mathrm{H}^{+}$

Alpha particles react with nitrate ions creating $\mathrm{NO}_{2}$ radicals, which oxidize $\mathrm{Pu}^{4+}$. The reaction has several variables including Pu concentration, nitric acid concentration, internal dose $(I)$, and time $(t)$. Rykov, et al. developed an equation $(6-8)$ based on experimental data describing the oxidation state distribution of any given Pu solution.

$$
\begin{aligned}
\Delta[P u(I V)] & =\Delta[P u(V I)]=\frac{k_{o x}[P u(I V)]_{0}-k_{r}[P u(V I)]_{0}}{k_{o x}+k_{r}} \times\left(1-e^{-\left(k_{o x}+k_{r}\right) t}\right) \\
k_{o x} & =1.8+\frac{14}{\left[H N O_{3}\right]} \times I \times 10^{-4} \\
k_{r} & =\frac{3.15 \times 10^{-3} \times[\mathrm{Pu}(I V)]^{2.3}}{\left[H N O_{3}\right]^{3}}
\end{aligned}
$$

When we apply this equation to our spent fuel solution, we observe that all the $\mathrm{Pu}$ in that solution is most likely in the +6 oxidation state (Figure 14). The results of the mathematical model were consistent with the lack of Pu deposition for all but the Pu-244 spike in the third dissolver solution test. Pu-244 did not get oxidized when it was added to the spent fuel solution, because the spent fuel had been diluted 50,000 -fold when the spike was added. 
A noteworthy feature of Figure 14 is that oxidation to $\mathrm{PuO}_{2}{ }^{2+}$ is more complete at less concentrated spent fuel samples. This is due to the decrease in plutonium concentration. At high concentrations, Pu undergoes disproportionation reactions that result in an equilibrated solution with some $\mathrm{Pu}^{4+}$ remaining (Rykov, 1979).

Hence, for the fourth dissolver solution test, we worked with the assumption that the Pu would have to be reduced before EMS could be performed. Fortunately, this is not a difficult feat and it may be accomplished chemically or electrochemically. As mentioned previously, $\mathrm{PuO}_{2}{ }^{2+}$ may not be directly reduced to $\mathrm{Pu}^{4+}$ electrochemically. However, $\mathrm{PuO}_{2}{ }^{2+}$ may be reduced to $\mathrm{Pu}^{3+}$ electrochemically (Eq. 9) (Cohen 1961) which is then easily electrochemically oxidized to $\mathrm{Pu}^{4+}$ (Eq. 2).

$$
\mathrm{PuO}_{2}^{2+}+4 \mathrm{H}^{+}+3 \mathrm{e}^{-} \stackrel{-0.3 \mathrm{~V}}{\longrightarrow} \mathrm{Pu}^{3+}+2 \mathrm{H}_{2} \mathrm{O}
$$

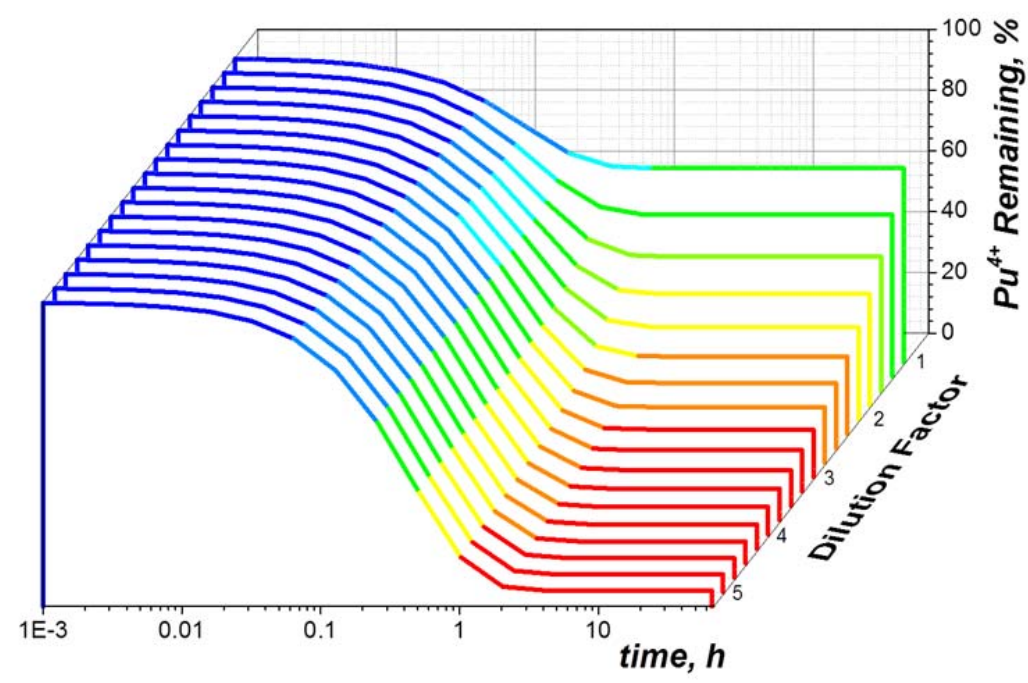

Figure 14. Effect of time and spent fuel concentration on the percent of plutonium in the +4 oxidation state according to Eq. 6 , assuming a starting point of $100 \% \mathrm{Pu}^{4+}$ and $0.3 \mathrm{M}$ nitric acid. Undiluted spent fuel is assumed $0.0126 \mathrm{M} \mathrm{Pu}$ with an internal dose of $20 \mathrm{~W} / \mathrm{L}$.

The electrochemical reduction method either requires two electrochemical cells in-line, or a second pass through the same cell for EMS. If it can be made $100 \%$ efficient, the electrochemical method is most desirable since no chemicals need to be added to the spent fuel. Electrochemical reduction is also the most rapid reduction method; the chemical reduction methods require several hours and electrochemical reduction requires several minutes or less. Speed of reduction will be particularly important with concentrated spent fuel where radiolysis is constantly occurring. Still, there are also chemical reduction methods that are easier to implement in the shortterm. 
$\mathrm{PuO}_{2}{ }^{2+}$ is reduced by hydrogen peroxide in $3 \mathrm{M}$ nitric acid (Maillard and Adnet 2001) (Eq. 10) or by Fe(II) (Eq. 11) (Newton 1975).

$\mathrm{PuO}_{2}^{2+}+\mathrm{H}_{2} \mathrm{O}_{2}+2 \mathrm{H}^{+} \rightarrow \mathrm{Pu}^{4+}+2 \mathrm{H}_{2} \mathrm{O}+\mathrm{O}_{2}$

$\mathrm{PuO}_{2}^{2+}+3 \mathrm{Fe}^{2+}+4 \mathrm{H}^{+} \rightarrow \mathrm{Pu}^{3+}+2 \mathrm{H}_{2} \mathrm{O}+3 \mathrm{Fe}^{3+}$

In order to test these reduction methods with neat solutions, it was necessary to produce an oxidized solution of $\mathrm{Pu}$. This was done chemically with $\mathrm{AgO}$ (Eq. 12) (Taduchi, et al. 2011).

$\mathrm{Pu}^{4+}+\mathrm{Ag}^{2+}+2 \mathrm{H}_{2} \mathrm{O} \rightarrow \mathrm{PuO}_{2}^{2+}+\mathrm{Ag}^{+}+2 \mathrm{H}^{+}$

After oxidation with $\mathrm{AgO}$, the resulting $\mathrm{PuO}_{2}{ }^{2+}$ could not be accumulated at the anodized glassy carbon as expected (Figure 15, red trace). However, if the Pu was electrochemically reduced in the MIC prior to EMS, the $\mathrm{Pu}^{3+}$ that resulted would accumulate at oxidizing potentials (Figure 15, blue trace). Electrochemical reduction in the MIC was accomplished in a flow-through procedure at $0.5 \mathrm{~mL} \mathrm{~min}{ }^{-1}$, cycling a 10 $\mathrm{mL}$ solution of $20 \mathrm{ppt} \mathrm{PuO}_{2}{ }^{2+}$ for 40 minutes. Only very low concentrations of Pu were used in this experiment, but it appears as though approximately $50 \%$ of the $\mathrm{Pu}$ deposited based on the relative intensity of the accumulation and strip fractions. Potentials less than or equal to $-0.1 \mathrm{~V}$ vs. $\mathrm{Ag} / \mathrm{AgCl}$ were sufficient to reduce $\mathrm{PuO}_{2}{ }^{2+}$, with no gains observed by applying a high overpotential (Figure 16).

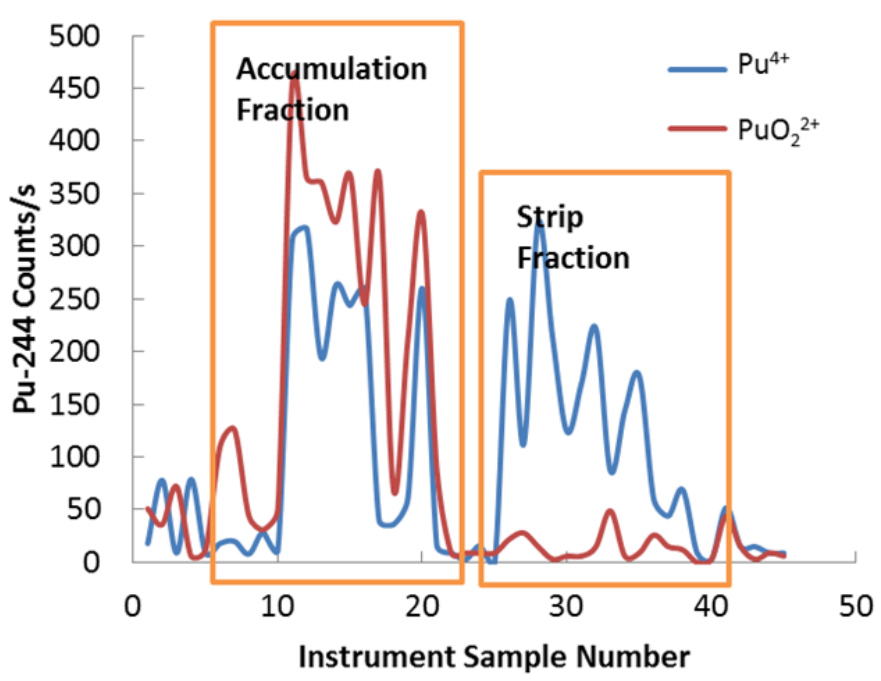

Figure 15. Analysis of EMS fractions by ICP-TOF-MS. Blue trace: $\mathrm{Pu}^{4+}$ was produced by electrochemical reduction of $\mathrm{PuO}_{2}{ }^{2+}$ at $-0.5 \mathrm{~V}$; Red trace: $\mathrm{PuO}_{2}{ }^{2+}$ was produced by addition of $1 \mathrm{mg} \mathrm{AgO}$ to $100 \mathrm{ppt} \mathrm{Pu}$ in $3 \mathrm{M} \mathrm{HNO}_{3}$. Pu was accumulated at $+1.1 \mathrm{~V}$ and stripped at $-0.2 \mathrm{~V}$.

Although $100 \%$ reduction efficiency has not been achieved electrochemically, the electrochemical method is more efficient than Pu reduction by hydrogen peroxide 
(Figure 17). The electrochemical reduction yielded a $50 \%$ reduction of $\mathrm{PuO}_{2}{ }^{2+}$, while $\mathrm{H}_{2} \mathrm{O}_{2}$ only reduced $20 \%$ of the $\mathrm{PuO}_{2}{ }^{2+}$. Still, reduction by hydrogen peroxide is an attractive chemical method since $\mathrm{H}_{2} \mathrm{O}_{2}$ degrades to $\mathrm{H}_{2} \mathrm{O}$. This has advantages over reduction by $\mathrm{Fe}^{2+}$, for example, which would require addition of large amounts of iron to the spent fuel solution that might affect subsequent stages of the reprocessing operations.

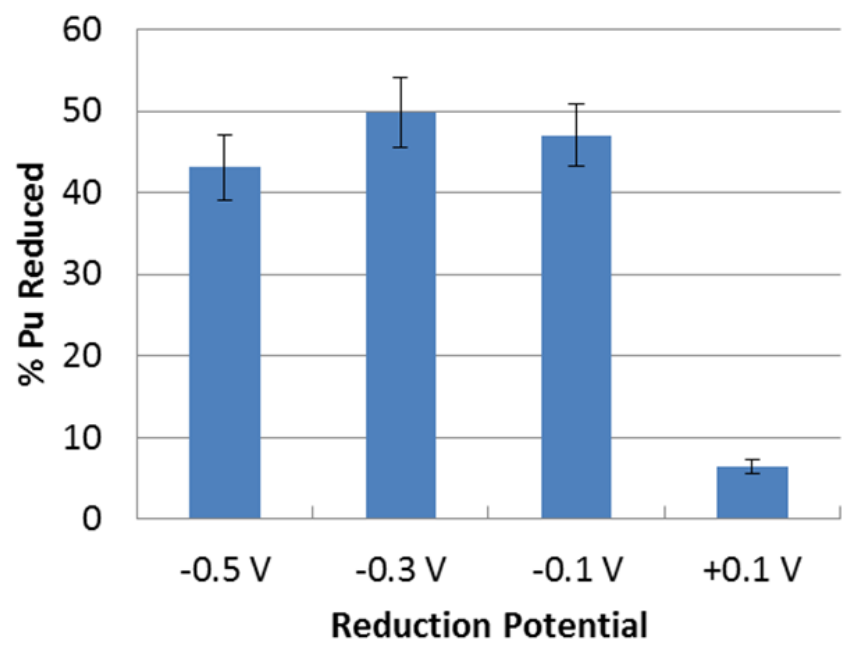

Figure 16. Effect of reduction potential on the percent of $\mathrm{PuO}_{2}{ }^{2+}$ reduced to $\mathrm{Pu}^{3+}$ in the MIC.

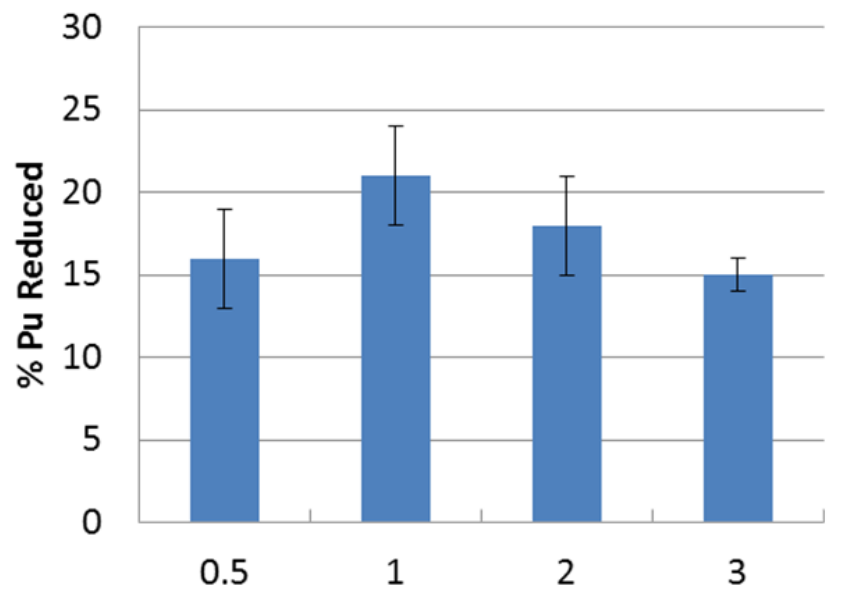

Hydrogen Peroxide, $30 \%$ added, $\mathrm{mL}$

Figure 17. The effect of hydrogen peroxide on the amount of $\mathrm{PuO}_{2}{ }^{2+}$ reduced to $\mathrm{Pu}^{4+}$ as observed by the resulting deposition efficiency for $\mathrm{Pu}$. $\mathrm{H}_{2} \mathrm{O}_{2}$ was added to $10 \mathrm{~mL}$ of 100 ppt $\mathrm{PuO}_{2}{ }^{2+}$.

Ultimately, the electrochemical reduction method would be used for spent fuel analysis, but the cell and procedure still need to be optimized. However, hydrogen peroxide as a reduction agent was used in the fourth dissolver solution test since the 
procedure could be implemented without additional equipment. The test achieved $18 \pm$ $3 \%$ deposition efficiency of Pu from spent fuel. The fourth dissolver solution test was the first to indicate that a significant amount of $\mathrm{Pu}$ in the spent fuel had accumulated on the anodized glassy carbon. A control in which no $\mathrm{H}_{2} \mathrm{O}_{2}$ was added was also analyzed as a comparison. From that solution, $3.6 \pm 0.7 \% \mathrm{Pu}$ accumulated. The two results are dissimilar with $98 \%$ certainty.

While the $18 \%$ deposition efficiency is far from the $>50 \%$ deposition efficiency typically achieved with neat Pu solutions, it does highlight the true problem that has in the past prevented deposition of $\mathrm{Pu}$ from spent fuel. With the problem now identified, progress can be made. Furthermore, $18 \%$ deposition efficiency is consistent with the $20 \%$ reduction efficiency of $\mathrm{PuO}_{2}{ }^{2+}$ by $\mathrm{H}_{2} \mathrm{O}_{2}$ that was observed with neat solutions. Greater reduction efficiencies were observed with electrochemical reduction which was used in the gamma spectroscopy experiment later.

In summary, very low deposition efficiencies for Pu have been observed in dissolver solution tests. However, the problem has been identified as radiolytic $\mathrm{Pu}$ oxidation and preliminary results indicate two solutions to the problem-chemical and electrochemical reduction-appear promising. Cell stability is no longer a problem with the aluminum counter electrode. Matrix effects remain a possible problem with more concentrated dissolver solution tests, but the matrix does not appear to affect $\mathrm{Pu}$ deposition from spent fuel once diluted more than 5,000-fold.

\section{Progress in Gamma Spectroscopy (Task 5)}

Ultimately, gamma spectroscopy will be used in situ for rapid non-destructive analysis of plutonium. This will be accomplished by monitoring the adsorbed $\mathrm{Pu}$ through the aluminum counter electrode before the Pu is stripped, or by monitoring the exit tubing after $\mathrm{Pu}$ is stripped. The latter detection scheme has been attempted.

Progress under this task includes monitoring of the fission products, in particular Cs-137, which gives a much stronger gamma signal than Pu isotopes. A computational model was also used to determine how much plutonium and what degree of separation would be needed for detection. Once the minimum amount of Pu needed was predicted, it was important to determine if the MIC had a sufficient capacity. Uranium was used as a surrogate for Pu to determine the capacity of the MIC. Finally, a preliminary test of the Pu EMS-gamma spectroscopy was performed with both in situ and ex situ gamma measurements.

\subsection{Monitoring of Fission Products by Gamma Spectroscopy}

Cs-137 was monitored in the outlet tubing with a Nal gamma detector during the second dissolver solution test to determine the rinse time required to completely remove all the fission and activation products from the MIC (Figure 18). The spent fuel sample was diluted 5,000 -fold from the original stock. The Cs-137 peak is clearly visible in the 
first 5 minutes of rinsing, but was decreased dramatically after 5 minutes. After 10 minutes the Cs-137 gamma signal was indistinguishable from the background, indicating that a 10 minute rinse time is sufficient for this sample. More concentrated samples may require more rinsing.
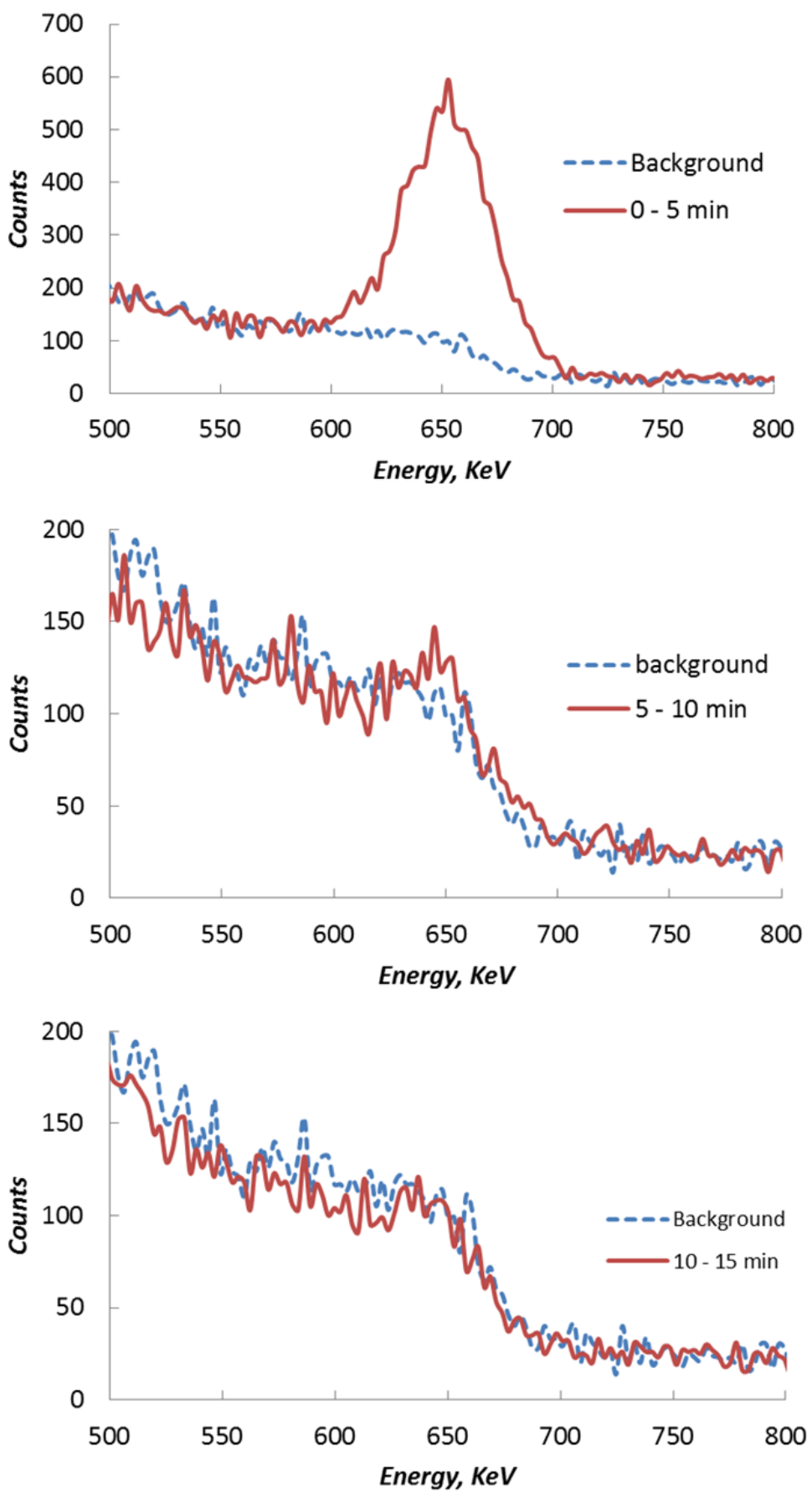

Figure 18. Gamma spectra showing the Cs-137 peak $(661.64 \mathrm{KeV})$ in spent fuel in the outlet tubing of the MIC (red trace), compared with the background spectrum (blue 
trace). Count time was 5 minutes. Top: first spectrum, middle: second spectrum, bottom: third spectrum.

\subsection{Computational Model}

Cesium is one of the most important interfering fission products for Pu gamma analysis because of its high yield, high activity and Compton scattering. Adequate separation of $\mathrm{Cs}$ from $\mathrm{Pu}$ in spent fuel will be essential for Pu gamma measurements. Figure 19 shows the effect of the cesium separation factor on gamma spectra according to a computational model. None of the Pu gamma lines are visible without separation. With a separation factor of 100 , some gamma lines may be detected, but the measurement precision is much improved with a 10,000-fold separation of Pu and Cs.

The uncertainties associated with the background at various separation factors and Pu concentrations were plotted in a three-dimensional graph for Pu-239, Pu-238, and Pu-240 (Figure 20). From these plots we determined that the MIC would be required to accumulate a minimum of $10 \mu \mathrm{g}$ of $\mathrm{Pu}$ which would make measurement of Pu-238 possible with acceptable uncertainty $(<10 \%)$ with a 100 -fold separation factor. $\mathrm{Pu}-239$ would be measureable also if $10 \mu \mathrm{g}$ were collected if a 10,000-fold separation factor were achieved. Pu-240, on the other hand, will be very challenging to measure quantitatively.

With this goal of $10 \mu \mathrm{g} \mathrm{Pu}$ accumulated, the capacity of the MIC was investigated.

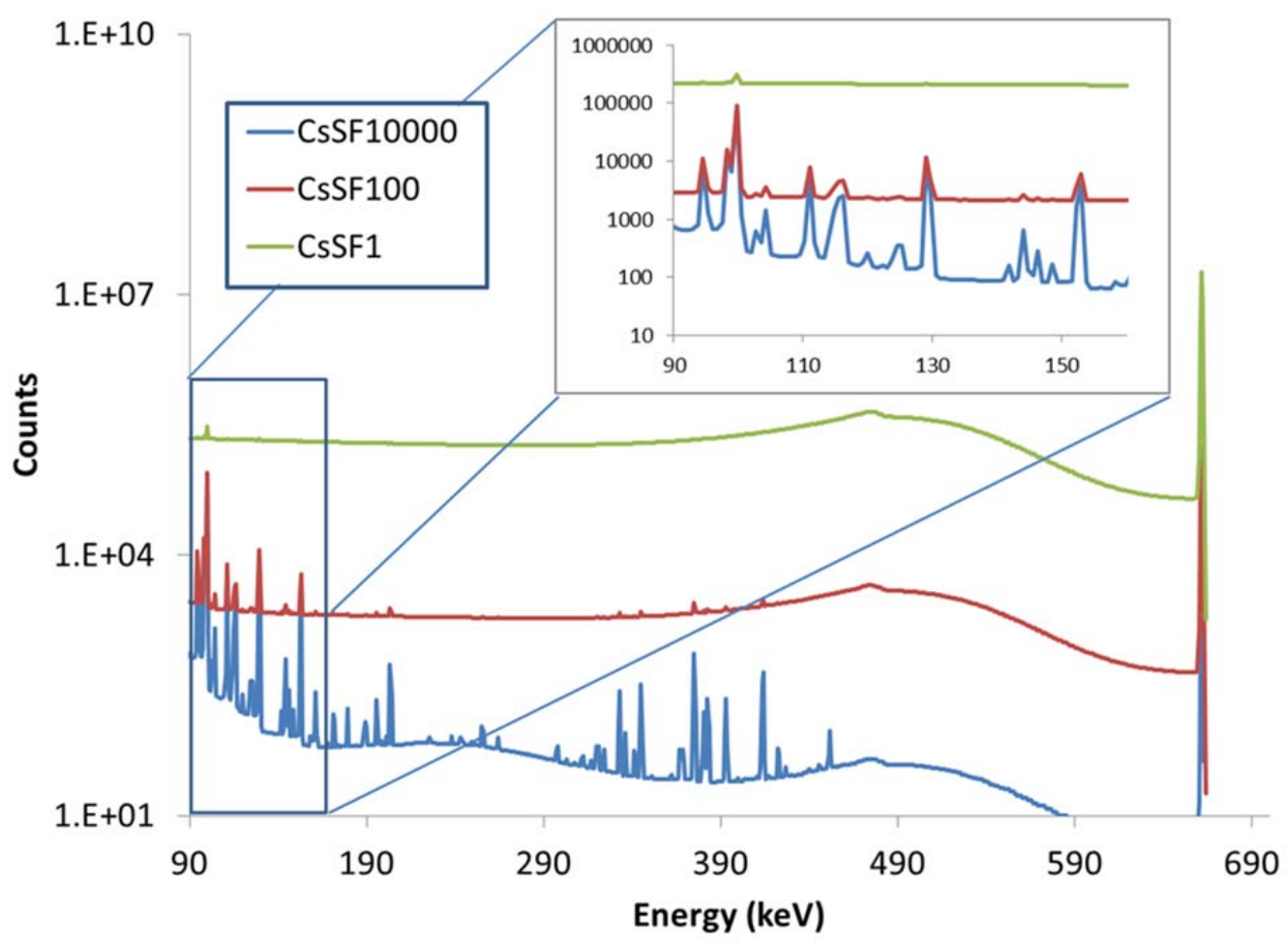


Figure 19. Modeled gamma spectra of Pu in spent fuel with different degrees of separation from Cs-137. Green: no separation, Red: separation factor $=100$, Blue: separation factor $=10,000$.
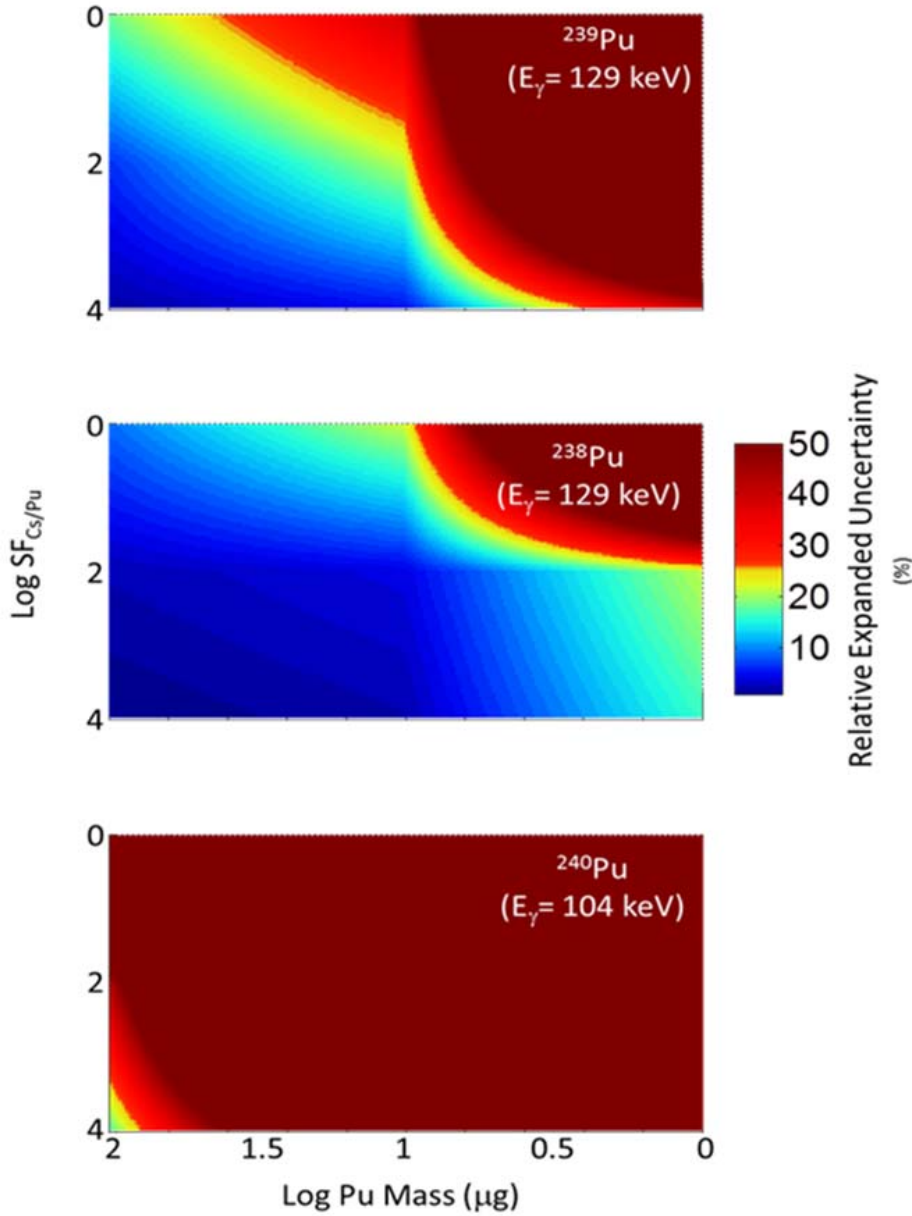

Figure 20. Three dimensional plots from a computational model indicating the effect of separation factors and Pu mass on the uncertainty associated with Pu gamma spectroscopy measurements. Top: Pu-239, middle: Pu-238, bottom: Pu-240. Note the logarithmic scales.

\subsection{Cell Capacity}

$\mathrm{Pu}$ and $\mathrm{U}$ are expected to adsorb to the anodized glassy carbon in a monolayer, therefore the cell's capacity is dependent on the working electrode surface area. U was used to determine the capacity of the MIC since high concentrations were required to begin to observe decreases in the deposition efficiency. By injecting $500 \mathrm{ppb} U$ in-line with ICP-TOF-MS, the effects of electrode saturation were apparent (Figure 21). The first $3 \mu \mathrm{g}$ of $U$ were accumulated after 9.5 minutes with an average deposition efficiency of $63 \%$. The last $3 \mu \mathrm{g}$ of $U$ required 16.75 minutes to accumulate with an average 
deposition efficiency of $36 \%$. The reason for the decrease in deposition efficiency is thought to be the decrease in the number of available binding sites for $U$.

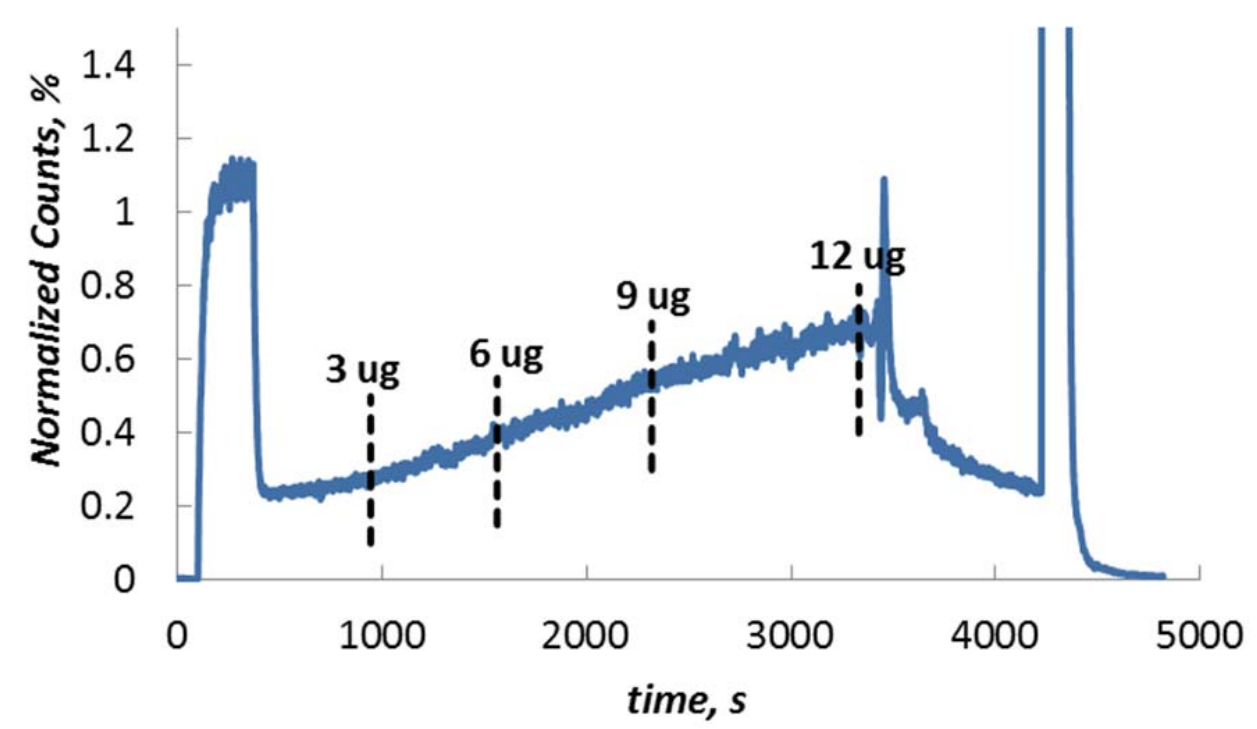

Figure 21. EMS-ICP-TOF-MS profile for $500 \mathrm{ppb} \mathrm{U}$ in $0.3 \mathrm{M} \mathrm{HNO}_{3}$. Flow rate $1 \mathrm{~mL}$ $\mathrm{min}^{-1}$. Potential applied was $+0.4 \mathrm{~V}$ to 5 minutes, followed by $-0.2 \mathrm{~V}$ to $1 \mathrm{~h} 15$ minutes, followed by $+1.1 \mathrm{~V}$. Mass marks indicate how much $\mathrm{U}$ was deposited. Counts are normalized to a strip peak height of $100 \%$.

Because there was a decrease in deposition efficiency with increased mass of $U$ injected, the relationship between $U$ injected and $U$ accumulated was not linear (Figure 22) - although it appears linear at low $U$ concentrations. The curve fits the Langmuir isotherm model (Eq. 13) (Do 1998).

$y=\frac{a b x}{(1+b x)}$

Here, $a$ is the maximum capacity of the electrode for $U$ and $b$ is proportional the deposition equilibrium of $U$ on anodized glassy carbon. In the electrochemical flow cell, flow rate and cell volume (gasket thickness) also affect $b$. The asymptote, $a$, was determined to be $48 \pm 12 \mu \mathrm{g} \mathrm{U}$. Assuming the surface area of the MIC is $45.6 \mathrm{~cm}^{2}$, this is equal to $2.66 \times 10^{15}$ atoms cm$~^{-2}$. Theoretically, assuming an ionic diameter for $U$ of $2.06 \times 10^{-8}$ (Douglas, et al. 1994), a monolayer would be $2.36 \times 10^{15}$, very close to the capacity calculated using the Langmuir isotherm model.

More importantly, we have shown that depositing $10 \mu \mathrm{g}$ of material in the MIC is possible. The most material actually deposited was $14.2 \mu \mathrm{g}$ of $\mathrm{U}$, but the curve extrapolates to approximately $50 \mu \mathrm{g}$. It can be assumed that the capacity will be similar for Pu, since Pu adsorbs to the same binding sites. However, the deposition equilibrium of Pu may be different than $U$. 
PNNL-22539

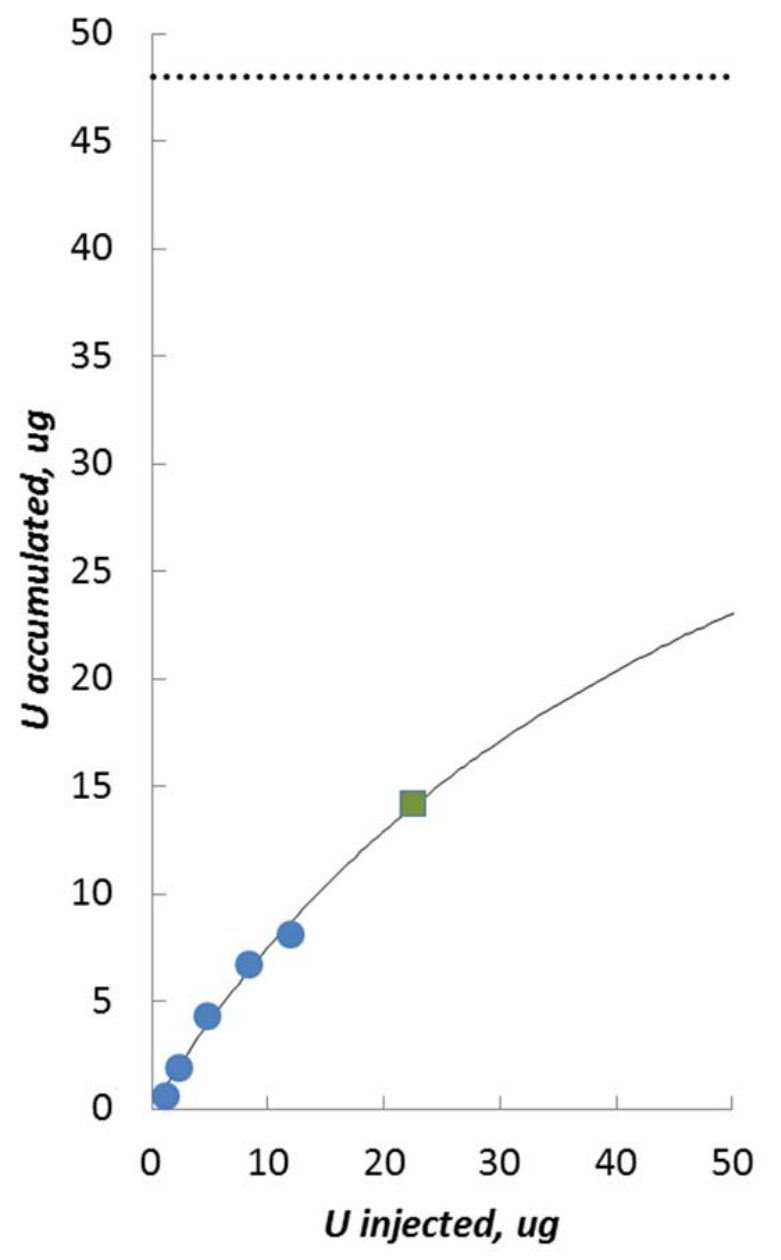

Figure 22. Effect of $U$ injected on $U$ accumulated. $U$ concentration was $238 \mathrm{ppb}$ (blue) and $500 \mathrm{ppb}$ (green). Dotted line shows asymptote of fit curve and MIC capacity for U.

\subsection{Gamma Detection of $\mathrm{Pu}$}

Gamma detection after EMS was done both in situ and ex situ with a 1:1 dilution of the 50x spent fuel stock (see section 2.3). For in situ detection, flow from the MIC was stopped after stripping Pu into a tubing coil while its contents were counted with a $\mathrm{Nal}$ gamma detector. For ex situ detection, fractions were collected and were counted with a high-purity germanium detector. Neither method was able to detect any $\mathrm{Pu}$ isotopes. However, it was apparent in the ex situ detection that the background was too high and that the rinse step should have been prolonged. Aliquots of the EMS fractions were also taken for mass spectrometry analysis which showed that Pu deposited with approximately $30 \%$ deposition efficiency. The amount of Pu injected was $20 \mu \mathrm{g}$, therefore, approximately $6 \mu \mathrm{g}$ Pu deposited, just falling short of the 10- $\mu \mathrm{g}$ target. Missing this target may have also contributed to the inability to detect any of the $\mathrm{Pu}$ isotopes by gamma spectroscopy. 


\subsubsection{In situ Detection}

The experimental set-up for in situ gamma detection is diagramed in Figure 23. Figure 24 shows a photograph of the actual experimental set-up. The spent fuel sample was pumped first into the reduction cell then to the EMS cell. The two cells were identical except that the EMS cell's glassy carbon working electrode was anodized and the reduction cell's working electrode was not. The working electrode in the reduction cell was maintained at $-0.3 \mathrm{~V}$ vs. $\mathrm{Ag} / \mathrm{AgCl}$ to reduce $\mathrm{PuO}_{2}{ }^{2+}$ to $\mathrm{Pu}^{3+}$. The working electrode in the EMS cell was maintained at $+1.1 \mathrm{~V}$ vs. $\mathrm{Ag} / \mathrm{AgCl}$ to oxidize $\mathrm{Pu}^{3+}$ to $\mathrm{Pu}^{4+}$ which was deposited on the anodized glassy carbon working electrode. When the desired volume of spent fuel was injected, the 2-position valve was switched to the carrier solution. After a rinsing period, the EMS cell potential was set at $-0.2 \mathrm{~V}$ vs. $\mathrm{Ag} / \mathrm{AgCl}$ to reduce $\mathrm{Pu}^{4+}$ to $\mathrm{Pu}^{3+}$ which has little affinity for the anodized glassy carbon, causing Pu to strip into the 3-mL coil.

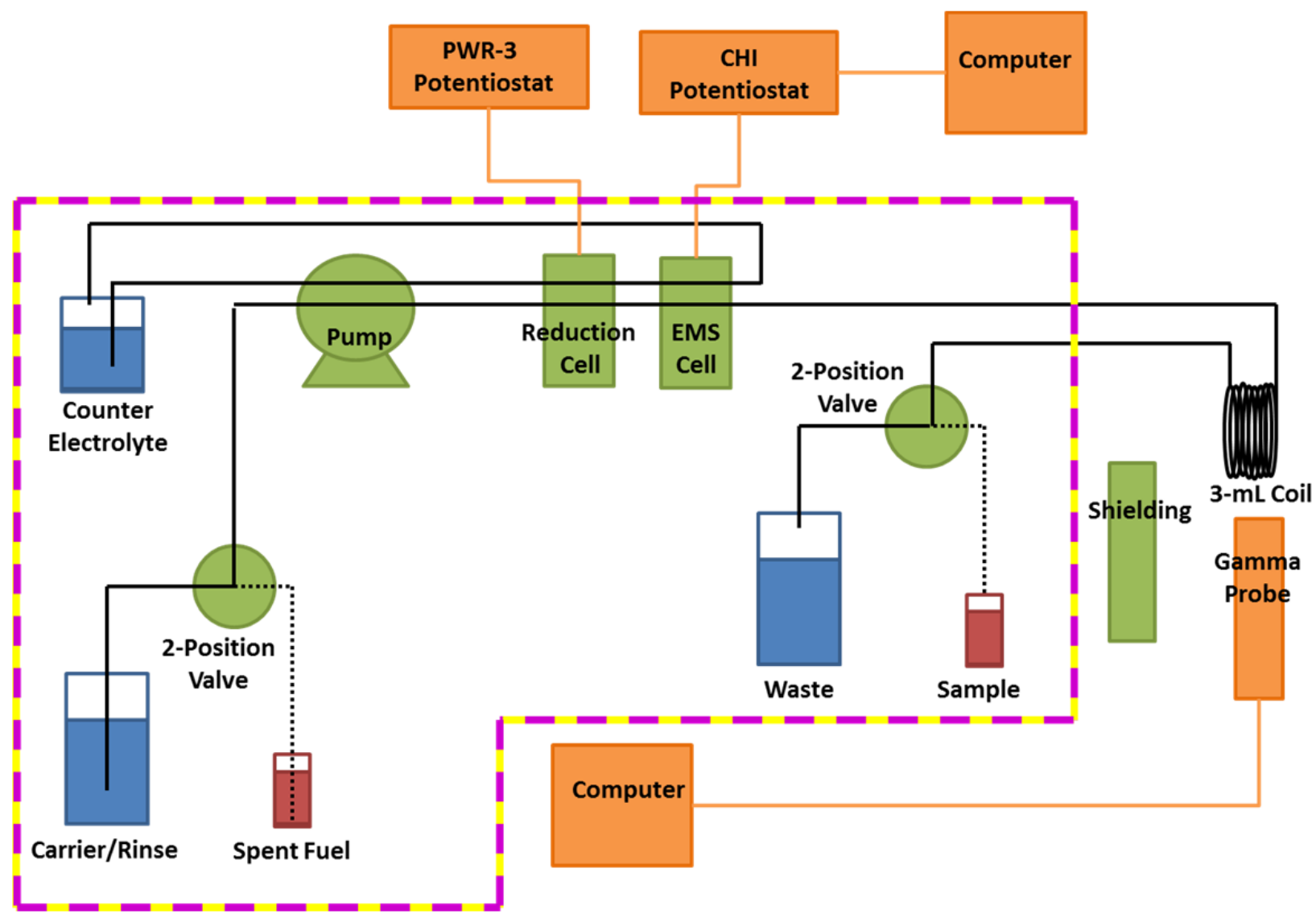

Figure 23. Diagram of the in situ EMS-gamma experiment set-up.

This two-cell set-up was initially tested with a 5,000-fold dilution of spent fuel. Flow rate was decreased from the usual $1.0 \mathrm{~mL} \mathrm{~min}^{-1}$ to $0.5 \mathrm{~mL} \mathrm{~min}{ }^{-1}$ since on-line electrochemical reduction had not been previously tested. Mass spectrometry analysis showed that $\mathrm{Pu}$ deposited with $30 \pm 5 \%$ efficiency. This is an improvement over the chemical reduction attempted in the fourth dissolver solution test. However, we cannot 
say whether the improvement is due to the electrochemical reduction method or the decreased flow rate.

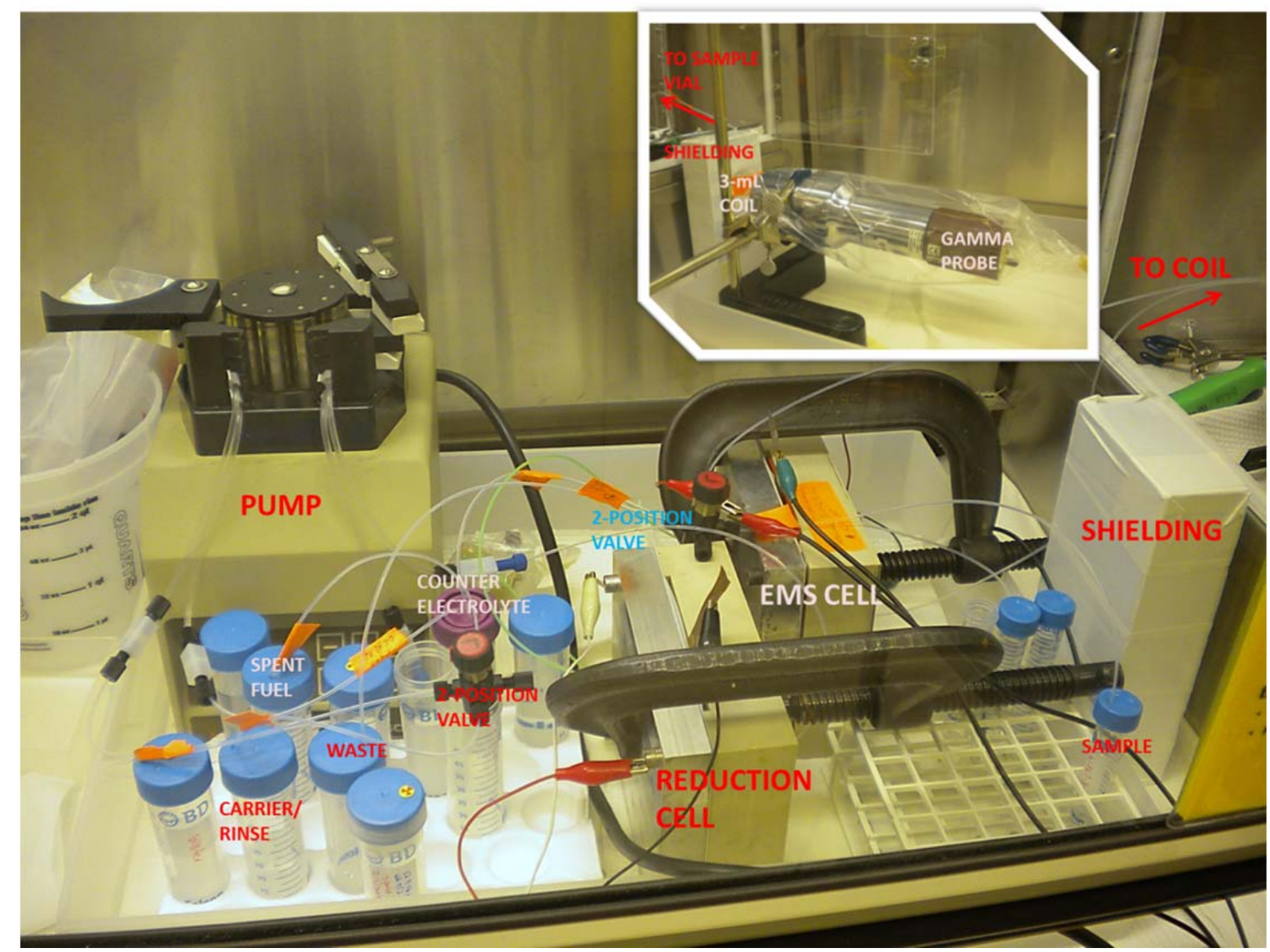

Figure 24. Photograph of the in situ EMS-gamma experiment. Inset photograph is the gamma probe and tubing coil.

The flow rate was further decreased to $0.2 \mathrm{~mL} \mathrm{~min}^{-1}$ for the gamma experiment since EMS experiments had not been done with Pu concentrations as high as $10 \mathrm{ppm}$. For the in situ gamma detection, once the plutonium reached the 3-mL coil the pump was stopped and the sample counted with a Nal detector. After 15 minutes of counting, the flow was resumed and the fraction that had been in the coil was collected for ex situ detection and mass spectrometry analysis. In addition to the Pu strip, gamma spectra were collected for the break-through and rinse steps (Figure 25). Compared to the break-through, the strip fraction had a much lower background, although it was still rather high, and no Pu isotope peaks were observed. However, the Nal detector may not have high enough resolution to detect Pu even under more optimal conditions. 
PNNL-22539

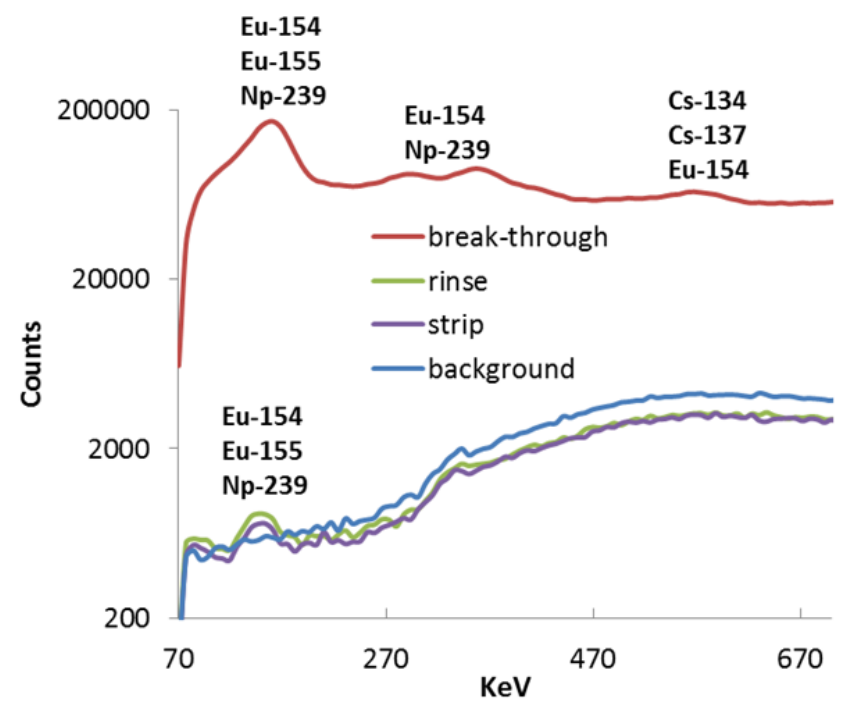

Figure 25. Gamma spectra from in situ monitoring of the EMS coil with a Nal detector. Count time 15 minutes.

\subsubsection{Ex situ Detection}

After in situ gamma detection was complete, the collected fractions were sent for counting by a high resolution detector. The break-through fraction is shown in Figure 26 and the strip fraction is shown in Figure 27 with $\mathrm{Pu}$ peak locations marked. As with in situ detection, no Pu peaks were observed and the background was still very high in the strip fraction. From the spectra, it appeared as though there was only a 10-fold reduction of the background in the strip fraction (reduced from $10^{5}$ to $10^{4}$ ). However, the activity for individual isotopes had been reduced by a factor of approximately 1000 for most radioactive isotopes (Table 5).

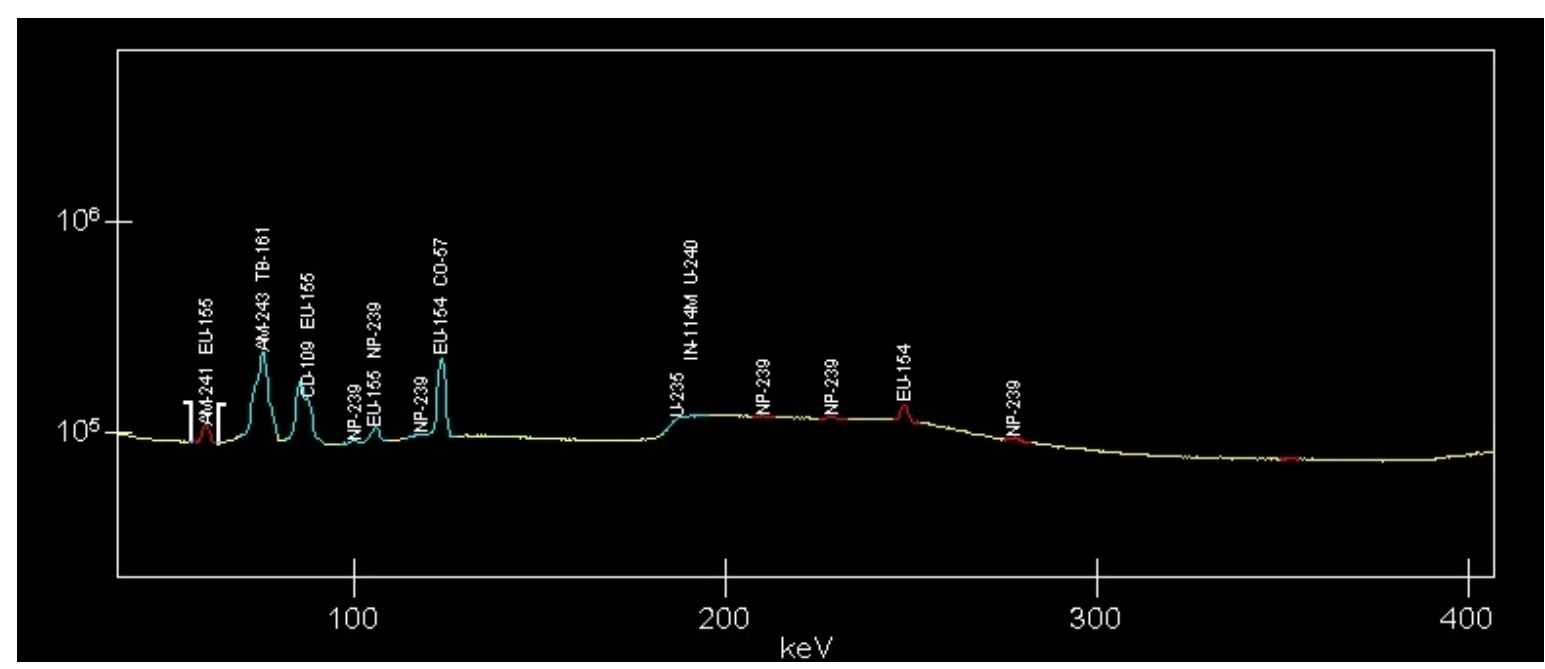

Figure 26. Gamma spectra for spent fuel break-through fraction. Count time 24 hours. Peaks were identified by Apex-Gamma software. 
PNNL-22539

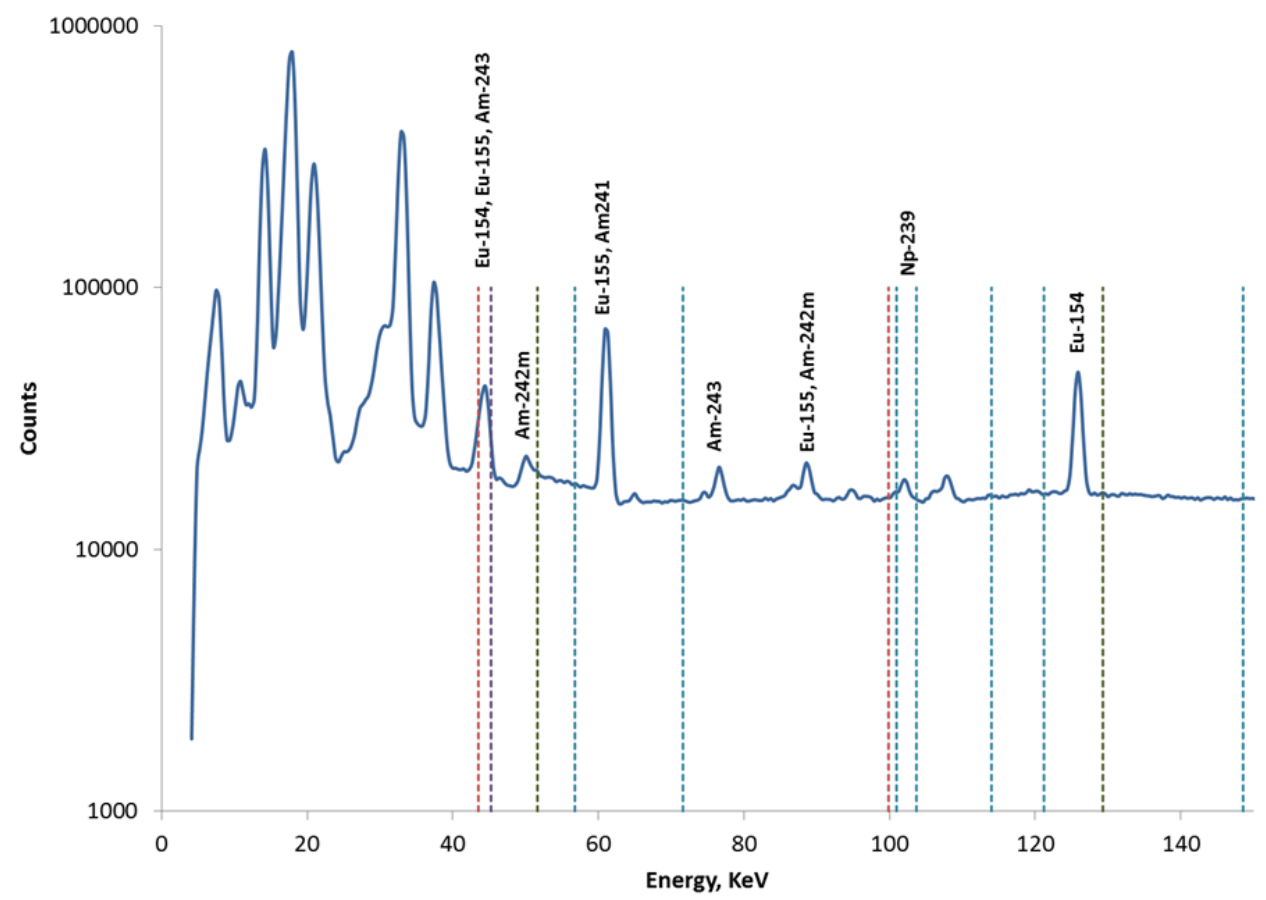

Figure 27. Gamma spectra for spent fuel strip fraction. Count time 24 hours. Peaks were identified by Apex-Gamma software. Pu peak locations marked with dashed lines. Red: Pu-238, Purple: Pu-240, Green: Pu-239, Blue: Pu-241.

Table 5. Isotope $y$ activities in break-through, rinse, and strip fractions.

\begin{tabular}{|c|c|c|c|c|c|}
\hline \multirow[t]{2}{*}{ Isotope } & \multirow{2}{*}{$\begin{array}{l}\text { Gamma } \\
\text { Energy, KeV }\end{array}$} & \multicolumn{3}{|c|}{ Activity, Bq } & \multirow{2}{*}{$\begin{array}{l}\text { Break- } \\
\text { through : } \\
\text { Strip Activity } \\
\text { Ratio }\end{array}$} \\
\hline & & $\begin{array}{l}\text { Break- } \\
\text { through }\end{array}$ & Rinse & Strip & \\
\hline Am-241 & 59.54 & $2.28 \times 10^{5}$ & 330 & 247 & 920 \\
\hline Cs-134 & $\begin{array}{l}\text { 563.25; 569.33; } \\
604.72 ; 795.86 ; \\
801.95 ; 1167.97 ; \\
1365.19\end{array}$ & $2.27 \times 10^{4}$ & 33.4 & 29.7 & 760 \\
\hline Cs-137 & 661.66 & $9.13 \times 10^{6}$ & $1.39 \times 10^{4}$ & $1.18 \times 10^{4}$ & 770 \\
\hline Eu-154 & $\begin{array}{l}\text { 123.07; 247.93; } \\
\text { 591.76; 692.42; } \\
\text { 723.30; 756.80; } \\
\text { 872.46; } 996.29 ; \\
1004.76 ; \\
1246.12 ; \\
1274.43 ; \\
1494.05 ; \\
1596.48 \\
\end{array}$ & $1.60 \times 10^{5}$ & 179 & 132 & 1200 \\
\hline Eu-155 & 105.31 & $4.54 \times 10^{4}$ & 52.0 & 36.8 & 1200 \\
\hline U-235 & 185.71 & $1.87 \times 10^{4}$ & 15.3 & 13.6 & 1400 \\
\hline
\end{tabular}


Even though the fission and activation products were reduced by a factor of nearly 1000 , the spectra background were not reduced as much as expected for even a 100 -fold separation factor based on the computational model (see Figure 19).

Therefore, more thorough extended rinse may be required.

\section{Conclusion}

The finding most important to the success of this project was that the oxidation state of the plutonium in the spent fuel was incompatible with the EMS accumulation process. Without addressing this problem, significant amounts of Pu would never be separated from the fission and activation products in spent fuel. Because the $\mathrm{Pu}$ oxidation state problem was unsuspected until the third dissolver solution test (in the project's final year) and not addressed until the last dissolver solution experiment for task 4, much remains to be done to address the problem sufficiently. A cell appropriate for Pu reduction needs to be designed and optimized for $100 \%$ reduction so that a quantitative spike would give a valid result.

The most important outstanding problem of the gamma spectroscopy experiment highlighted by task 5 appears to be in the adequate removal of fission and activation products. Further refinements need to be made in the cell designs to minimize dead volume and decrease rinse-out time. Pu deposition was also low at $30 \%$, considering that the flow rate was decreased from the usual $1.0 \mathrm{~mL} \mathrm{~min}^{-1}$ to $0.2 \mathrm{~mL} \mathrm{~min}^{-1}$. The low deposition efficiency may be due to low reduction efficiency or the matrix effects concentrated spent fuel. Therefore, more work is required to finally accomplish a successful Pu gamma detection-EMS experiment in a fuel reprocessing matrix but most if not all the major problems have been identified. 
PNNL-22539

\section{References}

Britton, S. C.; Evans, U. R. 1930. "The Passivity of Metals. Part VI. A Comparison between the Penetrating Power of Anions." Journal of the Chemical Society 1930:17731784.

Clark, W. J.; Park, S. H.; Bostick, D. A.; Duckworth, D. C.; Van Berkel, G. J. 2006. "Electrochemically Modulated Separation, Concentration, and Detection of Plutonium using an Anodized Glassy Carbon Electrode and Inductively Coupled Plasma Mass Spectrometry." Analytical Chemistry 78(24):8535-8542.

Cohen, D. 1961 "Electrochemical Studies of Plutonium lons in Perchloric Acid Solution." Journal of Inorganic Nuclear Chemistry 18:207-210.

Do, D. D. 1998. Adsorption Analysis: Equilibria and Kinetics. Imperial College Press, London, pp. 13-17.

Douglas, B.; McDaniel, D.; Alexander, J. 1994. Concepts and Models of Inorganic Chemistry, $3^{\text {rd }}$ ed. John Wiley \& Sons, Inc., New York, p. 226.

Duckworth, D. C.; Douglas, M.; Farmer III, O. T.; Lehn, S. A.; Liezers, M.; Peper, S. M.; Schwantes, J. M. 2008. "A Novel Approach to Near Real-Time Non-Destructive Analysis of Pu for Process Monitoring and Material Safeguards." Proceedings of INMM $49^{\text {th }}$ Annual Meeting.

Eddy Current Technology Incorporated "Conductivity of Metals Sorted by Resistivity." http://www.eddy-current.com/condres.htm Accessed 30 November 2012.

Green, M. A. Arrigo, L. M.; Liezers, M.; Orton, C.; Douglas, M.; Peper, S. M.; Schwantes, J. M.; Duckworth, D. C. 2009. "Electrochemically Modulated Separations for Destructive and Non-Destructive Analysis for Process Monitoring and Safeguard Measurements." Proceedings of INMM 50 th Annual Meeting.

Maillard, C.; Adnet, J. M. 2001. "Plutonium(IV) Peroxide Formation in Nitric Medium and Kinetics Pu(VI) Reduction by Hydrogen Peroxide." Radiochimica Acta 89: 485-490.

Newton, T. W. 1975. "The Kinetics of the Oxidation-Reduction Reactions of Uranium, Neptunium, Plutonium, and Americium in Aqueous Solutions." TID-26506

Okamoto, G. 1973. "Passive Film of 18-8 Stainless Steel Structure and Its Function." Corrosion Science 13: 471-489.

Ottmar, H.; Eberle, H. 1991. "The Hybrid K-Edge/K-XRF Desitometer: Principles Design - Performance." Institut für Kernphysik Report KfK 4590. 
Pretty, J. R.; Duckworth, D. C.; Van Berkel, G. J. 1998. "Electrochemical Sample Pretreatment Coupled On-Line with ICP-MS: Analysis of Uranium using an Anodically Conditioning Glassy Carbon Working Electrode." Analytical Chemistry 70(6):11411148.

Rykov, A. G.; Andreychuk, N. N.; Vasilev, V. Ya.; Ermokov, V. A. 1979. "Stability of Plutonium(IV) and Plutonium(VI) in Nitric Acid Solutions under Strong a-Irradiation." Journal of Radioanalytical and Nuclear Chemistry 51(2): 363-376.

Schwantes, J. M. 2002. "Equilibrium, Kinetic, and Reactive Transport Models for Plutonium." Texas A\&M University, College Station, TX: Radiochemistry. Dissertation for PhD. p. 311.

Taguchi, S.; Yamamoto, M.; Surugaya, N.; Kurosawa, A.; Hiyama, T.; Tanaka, T. 2011. "Determination of Trace Amounts of Plutonium in Low-Active Liquid Wastes from Spent Nuclear-Fuel Reprocessing Plants by Flow Injection-Based Solid-Phase Extraction/Electrochemical Detection System." Journal of Radioanalytical and Nuclear Chemistry 288: 435-441.

Tomiyasu, H.; Asano, Y. 1998. "Environmentally Acceptable Fuel Cycle: Development of a New Reprocessing System." Progress in Nuclear Energy 32(3/4): 421-427. 


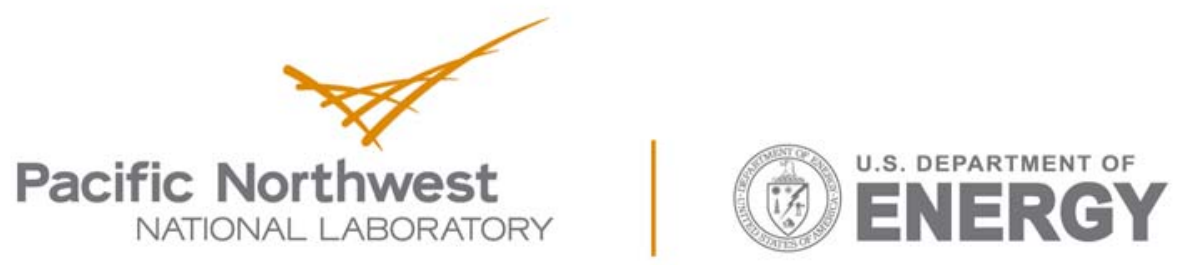

Proudly Operated by Battelle Since 1965

902 Battelle Boulevard

P.O. Box 999

Richland, WA 99352

1-888-375-PNNL (7665)

www.pnnl.gov 